\title{
Segregated anatomical input to sub-regions of the rodent superior colliculus associated with approach and defense
}

\author{
Eliane Comoli ${ }^{1 *}$, Plínio Das Neves Favaro ${ }^{1}$, Nicolas Vautrelle $^{2}$, Mariana Leriche ${ }^{2}$, Paul G. Overton $^{2}$ and \\ Peter Redgrave ${ }^{2}$
}

' Laboratory of Functional Neuroanatomy, Department of Physiology, School of Medicine of Ribeirão Preto, University of São Paulo, Ribeirão Preto, Brazil

2 Department of Psychology, University of Sheffield, Sheffield, UK

\section{Edited by:}

Jose L. Lanciego, University of

Navarra, Spain

\section{Reviewed by:}

Tomas Gonzalez-Hernandez, University of La Laguna, Spain Juan Mena-Segovia, Medical Research Council, UK

\section{*Correspondence:}

Eliane Comoli, Laboratory of Functional Neuroanatomy, School of Medicine of Ribeirão Preto, University of São Paulo, Av. Bandeirantes, 3900, CEP 14049-900 Ribeirão Preto,

São Paulo, Brazil.

e-mail: ecomoli@fmrp.usp.br
The superior colliculus (SC) is responsible for sensorimotor transformations required to direct gaze toward or away from unexpected, biologically salient events. Significant changes in the external world are signaled to SC through primary multisensory afferents, spatially organized according to a retinotopic topography. For animals, where an unexpected event could indicate the presence of either predator or prey, early decisions to approach or avoid are particularly important. Rodents' ecology dictates predators are most often detected initially as movements in upper visual field (mapped in medial SC), while appetitive stimuli are normally found in lower visual field (mapped in lateral SC). Our purpose was to exploit this functional segregation to reveal neural sites that can bias or modulate initial approach or avoidance responses. Small injections of Fluoro-Gold were made into medial or lateral sub-regions of intermediate and deep layers of SC (SCm/SCl). A remarkable segregation of input to these two functionally defined areas was found. (i) There were structures that projected only to $\mathrm{SCm}$ (e.g., specific cortical areas, lateral geniculate and suprageniculate thalamic nuclei, ventromedial and premammillary hypothalamic nuclei, and several brainstem areas) or $\mathrm{SCl}$ (e.g., primary somatosensory cortex representing upper body parts and vibrissae and parvicellular reticular nucleus in the brainstem). (ii) Other structures projected to both $\mathrm{SCm}$ and $\mathrm{SCl}$ but from topographically segregated populations of neurons (e.g., zona incerta and substantia nigra pars reticulata). (iii) There were a few brainstem areas in which retrogradely labeled neurons were spatially overlapping (e.g., pedunculopontine nucleus and locus coeruleus). These results indicate significantly more structures across the rat neuraxis are in a position to modulate defense responses evoked from $\mathrm{SCm}$, and that neural mechanisms modulating SC-mediated defense or appetitive behavior are almost entirely segregated.

Keywords: superior colliculus, segregated anatomical inputs, approach, defense

\section{INTRODUCTION}

For most animals, rapid reactions toward or away from unexpected, biologically salient events are crucial for survival in natural

\footnotetext{
Abbreviations: ACA, anterior cingulate area; aco, anterior commissure; AI, agranular insular area; AId, agranular insular área, dorsal part; APN, anterior pretectal nucleus; AQ, cerebral aqueduct; AUD, auditory area; bic, brachium of the inferior colliculus; BLA, basolateral amygdalar nucleus; BMA, basomedial amygdalar nucleus; CA1, field CA1, Ammon's horn; CA3, field CA3, Ammon's horn; cc, corpus callosum; CEA, central amygdalar nucleus; $\mathrm{CL}$, central lateral nucleus thalamus; $\mathrm{CM}$, central medial nucleus thalamus; $\mathrm{COA}$, cortical amygdalar nucleus; $\mathrm{CP}$, caudoputamen; cpd, cerebral peduncle; cst, corticospinal tract; CUN, cuneiform nucleus; DG, dentate gyrus; DMH, dorsomedial hypothalamic nucleus; DN, dentate nucleus; DTN, dorsal tegmental nucleus; ec, external capsule; ECT, ectorhinal area; em, external medullary lamina thalamus; ENT, entorhinal; fi, fimbria; FG, Fluro-Gold; FN, fastigial nucleus; fr, fasciculus retroflexus; fx, fornix; GPe, globus pallidus; GRN, gigantocellular reticular nucleus; GU, gustatory area; gVIIn, genu of the facial nerve; ICe, inferior colliculus, external nucleus; IMD, intermediolateral nucleus thalamus; ILA, infralimbic area; IP, interposed nucleus; IPN, interpeduncular nucleus; LA, lateral amygdalar nucleus; LAV, lateral vestibular nucleus; LC, locus ceruleus; LD, lateral posterior nucleus thalamus; LDT, laterodorsal tegmental nucleus; LG, lateral geniculate complex; LGd, lateral geniculate complex, dorsal part; LGv, lateral geniculate complex, ventral part; LH, lateral habenula; LHA, lateral hypothalamic area; LP, lateral posterior nucleus thalamus; MD, mediodorsal nucleus thalamus; MEA,
}

environments. A neural structure strongly implicated with initial behavioral responses to sensory events is the midbrain superior

medial amygdalar nucleus; MEV, midbrain trigeminal nucleus; MG, medial geniculate complex; ml, medial lemniscus; mlf, medial longitudinal fascicle; MM, medial mammillary nucleus; $\mathrm{MO}$, somatomotor areas; MOp, primary somatomotor area; MOs, secondary somatomotor area; MPT, medial pretectal area; MRN, midbrain reticular nucleus; $\mathrm{mtV}$, midbrain tract of the trigeminal nerve; $\mathrm{MV}$, medial vestibular nucleus; NI, nucleus incertus; NLL, nucleus of the lateral lemniscus; NOT, nucleus of optic tract; NPC, nucleus of posterior commissure; NPCc, nucleus of posterior commissure, caudal part; NPCr, nucleus of posterior commissure, rostral part; OP, olivary pretectal nucleus; opt, optic tract; OT, olfactory tubercle; PAG, periaqueductal gray; PAGdl, periaqueductal gray, lateral division; PAGl, periaqueductal gray, dorsolateral division; PAGvl, periaqueductal gray, ventrolateral division; PAR, parasubiculum; PARN, parvicellular reticular nucleus; PBl, parabrachial nucleus, lateral division; $\mathrm{PBm}$, parabrachial nucleus, medial division; PIR, piriform area; PL, pre-limbic area; PMd, dorsal premammillary nucleus; PO, posterior complex nucleus; POST, postsubiculum; PPN, pedunculopontine nucleus; PRC, precommissural nucleus, periaqueductal gray; PRE, presubiculum; PRN, pontine reticular nucleus; PRP, nucleus prepositus; PSV, principal sensory nucleus of the trigeminal; PTL, parietal region; PVT, paraventricular thalamic nucleus; py, pyramid; RE, nucleus reuniens; RH, rhomboid nucleus; RN, red nucleus; RR, midbrain reticular nucleus, retrorubral area; RSP, retrosplenial area; SAG, nucleus sagulum; SAI, stratum album intermediale; $\mathrm{SC}$, superior colliculus; $\mathrm{SCl}$, superior colliculus, lateral part; 
colliculus (SC; Dean et al., 1989). The SC has multisensory inputs that can guide gaze-shifts to bring prominent events into central vision (Stein and Meredith, 1993). It is also important for positioning the head in space during a variety of appetitive tasks, including foraging for food, predation, and nocifensive responses directed toward a source of pain (Wang and Redgrave, 1997; Furigo et al., 2010; Favaro et al., 2011). The SC has also been associated with defensive responses evoked by threatening stimuli (Dean et al., 1989). Potentially harmful looming stimuli activate the SC in a range of species (Westby et al., 1990; Liu et al., 2011) including humans (Billington et al., 2011), while stimulation of the SC can evoke defensive reactions extending from immediate arrest and freezing to violent defense-like locomotor responses (Sahibzada et al., 1986).

Significant changes in the external world are signaled to the SC through primary multisensory afferent projections that are spatially organized according to a precise retinotopic topography (Figure 1; Stein and Meredith, 1993). Multisensory inputs can be integrated to facilitate the detection of events close to sensory thresholds (e.g., the snap of a twig or slight movement in a bush), which can indicate the presence of predator or prey (Stein and Meredith, 1993). However for animals, where an unexpected event could indicate the presence of either a predator or prey, early decisions to approach or avoid are particularly important. It is, therefore, to be expected that approach/avoidance responses initiated by the SC will be subject to powerful contextual modulation (May, 2006).

For species where both predators and prey can appear from many directions (e.g., many species of fish, birds, and monkeys), contextual inputs from external structures which bias the SC to favor approach or avoidance, are probably directed to all parts of the retinotopically based topography. This would frustrate attempts to identify the source of afferents that promote approach or defense. However, in the case of rodents, their ecology dictates that predators are most frequently detected initially as movements in the upper visual field - which is represented in the medial portion of the SC's spatial map (Figure 1). Alternatively, appetitive stimuli (e.g., prey, offspring) are normally found in the lower visual field - which is represented in the lateral portion of the SC (Figure 1). Consequently, in rats, stimulation of lateral $\mathrm{SC}$ evokes approach-like and appetitive movements, while stimulation of medial SC induces defense-like responses (Dean et al.,

SCm, superior colliculus, medial part; scp, superior cerebellar peduncle; SG, supragenual nucleus; SGl, stratum griseum intermediale; SGN, suprageniculate nucleus; SGS, stratum griseum superficiale; sm, stria medullaris; $\mathrm{SNr}$, substantia nigra, reticular part; SNrdl, substantia nigra, reticular part, dorsolateral; SNrvm, substantia nigra, reticular part, ventromedial; SO, stratum opticum; SP, stratum profundum; sptV, spinal tract of the trigeminal nerve; SPV, spinal nucleus of the trigeminal; SSp-bfd, primary somatosensory area, barrel field; SSp-ll, primary somatosensory area, lower limb region; SS-n, primary somatosensory area, nose region; SSp-tr, primary somatosensory area, trunk region; SSp-ul, primary somatosensory area, upper limb region; SSs, supplemental somatosensory area; STN, subthalamic nucleus; SUV, superior vestibular nucleus; TEa, temporal association area; VIIn, facial nerve; VIS, visual area; VISC, visceral area; Vma, motor nucleus of the trigeminal, magnocellular part; VMH, ventromedial hypothalamic nucleus; VPM, ventral posteromedial nucleus thalamus; VPL, ventral posterolateral nucleus thalamus; VTA, ventral tegmental area; V4, forth ventricle; $\mathrm{ZI}$, zona incerta; $\mathrm{ZIv}$, l zona incerta ventral, lateral part; ZIv, m zona incerta ventral, medial part.

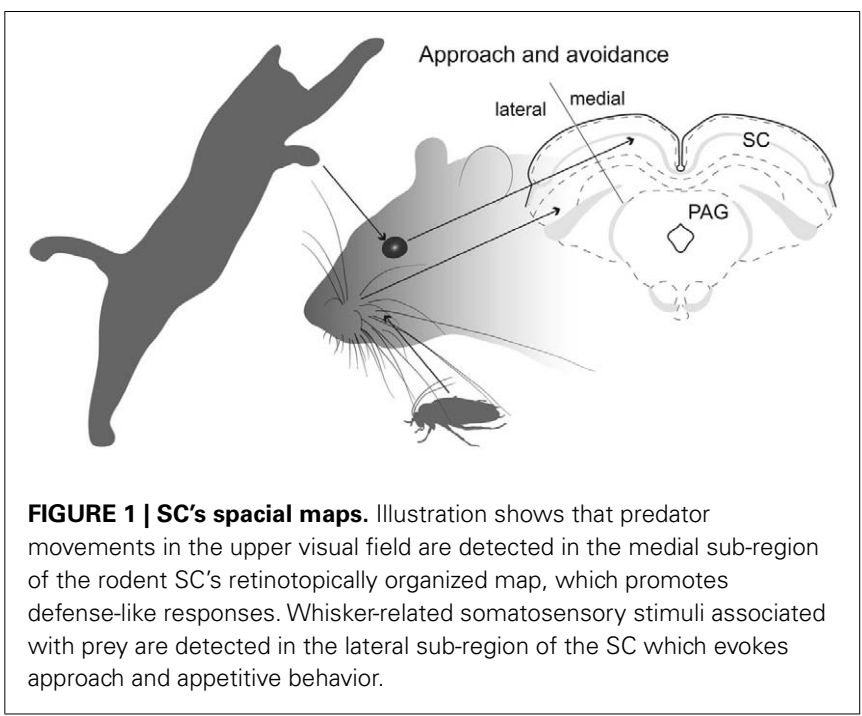

1986; Sahibzada et al., 1986). Moreover, exposing a rat to a predator (cat) induces selective neuronal activation in medial SC (Comoli et al., 2010), while allowing rats to hunt roaches (on the floor) causes selective activation in the lateral SC (Favaro et al., 2011). Using standard anatomical tracing procedures, the purpose of the present investigation was to exploit this remarkable functional segregation in the rat SC to reveal neural structures that can bias or modulate initial approach or avoidance behavioral reactions.

\section{MATERIALS AND METHODS}

To determine whether brain structures that provide afferent signals to the SC make differential contacts with the functionally segregated SC sub-regions associated with defense and appetitive responses, small injections of a sensitive retrograde tracer were made selectively into the medial and lateral sub-regions of the SC.

\section{SUBJECTS}

Experimental procedures were performed with male Wistar $(N=16)$ and female Hooded Lister $(N=2)$ rats (230-260 g). Animals were obtained from local breeding facilities of Ribeirão Preto and Sheffield laboratories respectively. The rats were kept under environmentally controlled conditions: temperature $\left(23 \pm 2^{\circ} \mathrm{C}\right)$, 12-h light/dark cycle (lights on at $7 \mathrm{AM}$ ), and had free access to water and standard laboratory diet. All animal husbandry and experimental procedures were performed in accordance with the National Institutes of Health Guidelines for the Care and Use of Laboratory Animals (NIH Publications No. 80-23, 1996). United Kingdom experiments were conducted in compliance with UK Govt. Home Office approval under section 5 (4) of the Animals (Scientific Procedures) Act 1986. Experimental protocols also received prior approval of the relevant Institutional Ethics Committees. Effort was made to minimize the number of animals used and their suffering.

\section{RETROGRADE TRACING PROCEDURES}

Rats were anesthetized with an intraperitoneal injection of a mixture of ketamine, xylazine, and acepromazine (100:20:3 mg/kg; União Farmacêutica Nacional S/A, Embu-Guaçu, São Paulo, 
Brazil; Laboratórios Calier S/A, Barcelon, Spain; Rhobifarma Indústria Farmacêutica Ltda, São Paulo, São Paulo, , Brazil) or a mixture of ketamine (Ketaset ${ }^{\circledR}, 0.765 \mathrm{ml} / \mathrm{kg}$ ) and xylazine (Rompun $^{\circledR}, 1.1 \mathrm{ml} / \mathrm{kg}$ ). The sensitive retrograde tracer FluoroGold (solution of 2.5 or $4 \%$ - Fluorochrome, Denver, CO, USA) was injected unilaterally into either the medial (AP $6.0 \mathrm{~mm}$ caudal to bregma; ML $0.7 \mathrm{~mm}$; DV $3.2 \mathrm{~mm}$ from the brain surface) or lateral (AP $6.0 \mathrm{~mm}$; ML $2.4 \mathrm{~mm}$; DV $4.5 \mathrm{~mm}$ ) sub-region of the SC (Paxinos and Watson, 2007). Deposits were made iontophoretically through a glass micropipette (tip diameter, $25 \mu \mathrm{m}$ ) using a constant-current generator (model CS3, Midgard Electronics, Canton, MA, USA) to deliver $+2.5 \mu \mathrm{A}$, with 7 -s on-off duty cycle for $7 \mathrm{~min}$.

\section{HISTOLOGY}

After a survival period of 7-12 days, the animals were deeply anesthetized with pentobarbitone sodium (Pentoject ${ }^{\circledR}, 0.6-0.8 \mathrm{ml} / \mathrm{kg}$ ) or a mixture of ketamine and xylazine $(100: 20 \mathrm{mg} / \mathrm{kg}$, ip.) and perfused transcardially with a brief saline rinse followed by an ice-cold solution of $4 \%$ paraformaldehyde in a $0.1-\mathrm{M}$ phosphate buffer at $\mathrm{pH}$ 7.4. Two hours later the brains were removed from the skull and cryoprotected with $20 \%$ sucrose in $0.1 \mathrm{M}$ phosphate buffer at $4^{\circ} \mathrm{C}$. Brains were frozen and coronal sections $(30 \mu \mathrm{m})$ were obtained using a microtome (Leika Microsystems, Germany). For two cases, sections were collected directly onto slides, allowed to dry in a light-protected box and coverslipped with DPX mountant. An adjacent series was stained with cresyl violet to serve as an anatomical reference. The location of transported FluoroGold in the tissue of these animals was determined by fluorescence microscopy.

Fluoro-Gold in all other cases was determined by immunohistochemistry performed according to published protocols (Schmued and Fallon, 1986; Pieribone and Aston-Jones, 1988). Briefly, sections were incubated with rabbit anti-Fluoro-Gold antibody (1:5,000; Chemicon International, Temecula, CA, USA, lot \# 0606034308; $72 \mathrm{~h}$ ) and washed in potassium phosphatebuffered saline (KPBS; pH 7.4). Next, sections were incubated in a solution of biotinylated goat anti-rabbit IgG (Vector Laboratories, Burlingame, CA, USA). After being washed, sections were incubated in ABC reagent (ABC Elite Kit; Vector Laboratories). The peroxidase reaction-product was visualized using the glucose oxidase procedure (Itoh et al., 1979) and the metal free 3,3' diaminobenzidine tetrahydrochloride (DAB; Sigma, St Louis, MO, USA) as a chromogen. Sections were exposed for $10 \mathrm{~min}$ to a $0.02 \%$ chromogen solution containing $0.3 \%$ nickel-ammonium sulfate in $0.05 \mathrm{M}$ phosphate buffer ( $\mathrm{pH} 7.4$ ) and glucose oxidase, followed by the addition of $\beta$-D-glucose to produce a blueblack product. The reaction was terminated by washing in KPBS, $\mathrm{pH} 7.4$.

After processing, sections were mounted on gelatinized slides, dehydrated, and coverslipped with DPX (Sigma). An adjacent series was stained with thionin to serve as an anatomical reference for the distribution of Fluoro-Gold labeling.

\section{MICROSCOPY AND DATA PLOTTING}

Excluding the olfactory bulb, sections throughout the brain were analyzed for the presence of retrograde labeling. Non-processed sections were observed with a fluorescent microscope equipped with episcopic illumination (Nikon Eclipse E800M, Kingstonupon-Thames, UK) and UV excitation filter (330-380 nm). Sections subjected to immunohistochemistry were examined under brightfield illumination (Leika DM 2500). Fluoro-Gold deposits in the injection site and retrogradely labeled perikarya were plotted with the aid of a camera Lucida onto maps from adjacent thionin-stained sections. Brain structures were identified with reference to the stereotaxic atlas of Swanson (2004). Photomicrographs were obtained with microscope-mounted digital cameras and adjusted for contrast and brightness with Adobe Photoshop CS3 (version 10.0.1; Adobe Systems, Mountain View, CA, USA). Line drawings were prepared with Adobe Illustrator CS3 (version 13.0.1; Adobe Systems).

The pattern of layering within the rodent SC was identified according to the nomenclature established in previous investigations (Sahibzada et al., 1986; Telford et al., 1986; Coizet et al., 2007; Favaro et al., 2011): superficial layers (SZ, stratum zonale; SGS, stratum griseum superficiale; $\mathrm{SO}$, stratum opticum); the intermediate layers (SGI, stratum griseum intermediale; SAI, stratum album intermediale); and the deep layers (SGP, stratum griseum profundum; and SAP, stratum album profundum; Figure 2). However, in this paper we follow the widely adopted convention of using the term "deep layers" to refer to both intermediate and deep layers. A line approximating the horizontal meridian bisected the SC into medial-upper and lateral-lower field sub-regions (Telford et al., 1986; Figure 2).

\section{AFFERENT CELL DENSITIES}

To provide an estimate of the potential importance of afferent control exercised over the medial and lateral sub-regions of the SC by different structures, we determined the relative densities of retrogradely labeled cells in afferent structures. Thus for each structure, a standard graticule $\left(0.5 \mathrm{~mm} \times 0.5 \mathrm{~mm}\right.$ area $\left.=0.25 \mathrm{~mm}^{2}\right)$ was placed over the area within the structure that contained the maximum density of retrogradely labeled cells. The number of cells contained within the graticule was recorded. The resulting numbers were then converted to a four-point ordinal density measure: low (1-40 cells); low-medium (41-80 cells); high-medium

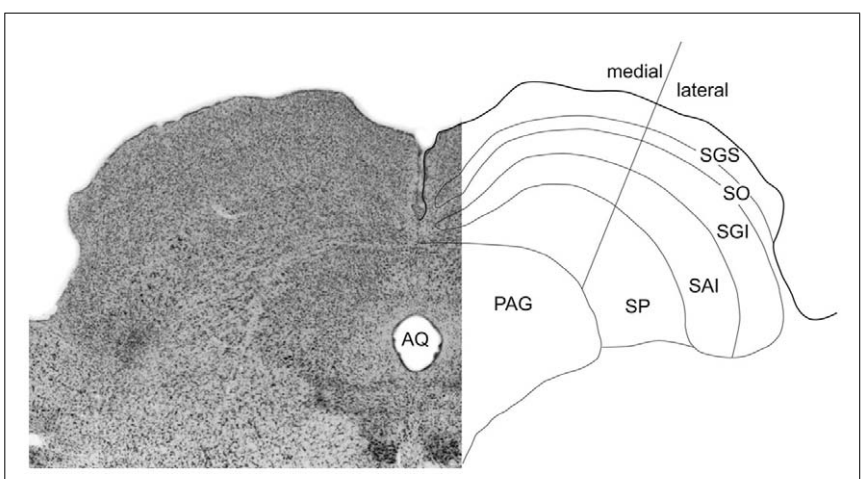

FIGURE 2 | Sub-regions of the SC. On the left a photomicrograph of the SC's cytoarchitecture (Nissl stained). Layers are identified in a reflected schematic (right). The medial/lateral sub-regions approximates the horizontal meridian in the collicular map of visual space. 
(81-120 cells); and high (>120 cells). For the two illustrated cases these numbers were entered into Table 1.

\section{RESULTS}

The purpose of the present study was to exploit the regional segregation of approach and defense-related functions in the rodent SC to identify afferent structures throughout the brain that have the potential to exercise control over these functions. Our strategy was to inject small amounts of a sensitive tracer specifically into the medial (defense) or lateral (approach) territories of the rat SC and determine the location of retrograde labeled neurons.

The injection sites of all animals used in the present study are illustrated in Figure 3. There were nine cases with injections into the medial SC and nine injections into lateral SC. From the material illustrated in Figure 3 it is clear that, with few exceptions (cases 06 and 0201 medial; and 01 lateral, which may have extended into the overlying superficial layers), the deposits of tracer were confined in SC deep layers. Thus, none of the medially located injections extended ventrally into the adjacent periaqueductal gray, while only the laterally placed injection of case 78 may have extended slightly into the underlying mesencephalic reticular formation.

From this population of injections we chose two cases (43medial; and 02-lateral - colored dark gray in Figure 3) whose data best represent the two groups of injection sites. Photomicrographs of the injection sites of these two demonstration cases and adjacent cytoarchitecture of SC are presented in Figures 4A and C, B and $D$ respectively.

The injection sites of the demonstration cases (43 and 02) were confined entirely to the SC deep layers and involved no external structures. A record of the neurons retrogradely labeled from these injection sites throughout the brain are plotted in Figure 5 and the relative densities of retrogradely labeled cells are displayed in Table $\mathbf{1}$. Unless specifically mentioned, the locations of retrograde labeling in these two representative cases were also observed in all other members of their respective medial or lateral groups. Somewhat to our surprise, the patterns of retrograde labeling, and hence, the inputs to these two functionally distinguished regions of the SC, were almost entirely segregated. Consequently, we will describe the afferent projections according to whether they are: (i) structures that convey exclusive projections to lateral or medial sub-regions of the rodent SC: (ii) structures with projections that are topographically organized to medial and lateral sub-regions; and (iii) structures whose projections have overlap to medial and lateral sub-regions of SC. We will also provide an indication of how significant the input into the different sub-regions of the SC is likely to be (strong, moderate, weak). We will offer an analysis of the functional implications of the patterns of retrograde tracing we observed in the "Discussion" section.

\section{PROJECTIONS EXCLUSIVE TO THE MEDIAL-DEFENSE SUB-REGION OF THE SC}

This section describes the afferent structures that project to the SC deep layers, but make contact only with the medial sub-region. The most obvious general observation was that many structures located throughout the entire neuraxis make contact exclusively
Table 1 | Relative densities of retrogradely labeled cells in the afferent structures for the two cases illustrated in Figure $5^{\mathrm{a}}$.

\begin{tabular}{|c|c|c|}
\hline & $\begin{array}{l}\text { SCm ipsi/ } \\
\text { contra }\end{array}$ & $\begin{array}{l}\text { SCl ipsi/ } \\
\text { contra }\end{array}$ \\
\hline \multicolumn{3}{|l|}{ EXCLUSIVE PROJECTIONS } \\
\hline \multicolumn{3}{|l|}{ Cortex (layer 5) } \\
\hline Agranular insular area (Al) & $-1-$ & $+/-$ \\
\hline Auditory (AUD) & $+1-$ & $-1-$ \\
\hline Ectorhinal (ECT) & $+1-$ & $-1-$ \\
\hline Gustatory (GUS) & $-1-$ & $+1-$ \\
\hline Infralimbic (ILA) & $+1-$ & $-1-$ \\
\hline Parietal region (PTL) & $+1-$ & $-1-$ \\
\hline Prelimbic (PL) & $+1-$ & $-1-$ \\
\hline Primary somatosensory area, nose region (SSp-n) & $-1-$ & $+/-$ \\
\hline Lower limb region (SSp-II) & $+1-$ & $-1-$ \\
\hline Upper limb region (SSp-ul) & $-1-$ & $+1-$ \\
\hline Trunk region (SSp-tr) & $+/-$ & $-1-$ \\
\hline Retrosplenial granular (RSP) & $++/-$ & $-1-$ \\
\hline Temporal association area (TEa) & $++/-$ & $-1-$ \\
\hline Visceral area (VISC) & $-1-$ & $+/-$ \\
\hline Visual area (VIS) & $++/-$ & $-1-$ \\
\hline \multicolumn{3}{|l|}{ Hippocampal formation } \\
\hline Postsubiculum (POST) & $+/-$ & $-1-$ \\
\hline \multicolumn{3}{|l|}{ Diencephalon } \\
\hline \multicolumn{3}{|l|}{ Hypothalamus } \\
\hline Dorsal premammillary nucleus (PMd) & $+++/-$ & $-1-$ \\
\hline Ventromedial hypothalamic nucleus (VMH) & $++/++$ & $-1-$ \\
\hline \multicolumn{3}{|l|}{ Thalamus } \\
\hline Lateral posterior nucleus thalamus (LP) & $+1-$ & $-1-$ \\
\hline Suprageniculate nucleus (SGN) & $+/-$ & $-1-$ \\
\hline Lateral geniculatecomplex, ventral (LGv) & $++++/+$ & $-1-$ \\
\hline \multicolumn{3}{|l|}{ Pre-tectum } \\
\hline Anterior pretectal nucleus, dorsal part (APN) & $+/+$ & $-1-$ \\
\hline Medial pretectal area (MPT) & $+/+$ & $-1-$ \\
\hline Olivary pretectal nucleus (OP) & $+/+$ & $-1-$ \\
\hline \multicolumn{3}{|l|}{ Brainstem } \\
\hline Cuneiform nucleus (CUN) & $+/+$ & $-1-$ \\
\hline Laterodorsal tegmental nucleus (LDT) & $+/+$ & $-1-$ \\
\hline Nucleus incertus (NI) & $+/+$ & $-1-$ \\
\hline Nucleus prepositus (PRP) & $-1++$ & $-1-$ \\
\hline Nucleus sagulum (SAG) & $++/+$ & $-1-$ \\
\hline Parvicellular reticular nucleus (PARN) & $-1-$ & $-1+$ \\
\hline $\begin{array}{l}\text { Precommissural nucleus, periaqueductal grey } \\
\text { (PRC) }\end{array}$ & $++/+$ & $-1-$ \\
\hline Pontine reticular nucleus (PRN) & $+/+$ & $-1-$ \\
\hline Superior colliculus, intermediate layers (SC) & $+/+$ & $-1-$ \\
\hline Supragenual nucleus (SG) & $-/++++$ & $--1-$ \\
\hline
\end{tabular}

(Continued)

with this subdivision of the deep SC. These structures may be classified as follows.

\section{Cerebral cortex and hippocampal formation}

Retrogradely labeled neurons were found ipsilaterally in several isocortical areas and to a lesser extent in the hippocampal 


\begin{tabular}{|c|c|c|}
\hline & $\begin{array}{l}\text { SCm ipsi/ } \\
\text { contra }\end{array}$ & $\begin{array}{l}\text { SCI ipsi } \\
\text { contra }\end{array}$ \\
\hline \multicolumn{3}{|c|}{ DIFFERENTIALTOPOGRAPHY PROJECTIONS } \\
\hline \multicolumn{3}{|l|}{ Cortex } \\
\hline \multicolumn{3}{|c|}{ Anterior cingulate area (ACA) } \\
\hline rostral & $+/-$ & $-1-$ \\
\hline caudal & $-1-$ & $+/-$ \\
\hline \multicolumn{3}{|c|}{ Primary somatomotor area (MOp) } \\
\hline rostral & $-1-$ & $+/-$ \\
\hline caudal & $+/-$ & $-1-$ \\
\hline \multicolumn{3}{|c|}{ Primary somatosensory: dysgranular region (S1 dz) } \\
\hline rostral & $-1-$ & $+/-$ \\
\hline caudal & $+/-$ & $-1-$ \\
\hline \multicolumn{3}{|c|}{ Primary somatosensory: barrel field (SSp-bld) } \\
\hline rostral & $-1-$ & $+/-$ \\
\hline caudal & $+/-$ & $-1-$ \\
\hline \multicolumn{3}{|c|}{ Secondary somatomotor area (MOs) } \\
\hline rostral & $-1-$ & $+1-$ \\
\hline caudal & $-1+$ & $+/-$ \\
\hline \multicolumn{3}{|c|}{ Supplemental somatosensory area (SSs) } \\
\hline rostral & $-1-$ & $+/-$ \\
\hline caudal & $+/-$ & $-1-$ \\
\hline \multicolumn{3}{|l|}{ Diencephalon } \\
\hline \multicolumn{3}{|l|}{ Thalamus } \\
\hline \multicolumn{3}{|l|}{ Zona incerta ventral (ZI) } \\
\hline rostrolateral & $++/-$ & $-1-$ \\
\hline caudolateral & $+/-$ & $-1-$ \\
\hline rostromedial & $-1-$ & $-1-$ \\
\hline caudomedial & $-1-$ & $+++/-$ \\
\hline \multicolumn{3}{|l|}{ Pre-tectum } \\
\hline \multicolumn{3}{|c|}{ Nucleus of posterior commissure (NPC) } \\
\hline rostral & $+/+$ & $-1-$ \\
\hline caudal & $-1-$ & $++/-$ \\
\hline \multicolumn{3}{|l|}{ Brainstem } \\
\hline \multicolumn{3}{|c|}{ Nucleus of the lateral lemniscus (NLL) } \\
\hline dorsal & $+/++$ & $-1-$ \\
\hline ventral & $+/++$ & $-1+$ \\
\hline \multicolumn{3}{|l|}{ Parabrachial area, } \\
\hline medial division (PBm) & $-1-$ & $-1+$ \\
\hline lateral division (PBI) & $+/+$ & $-1-$ \\
\hline \multicolumn{3}{|c|}{ Periaqueductal gray (PAG) dorsolateral } \\
\hline rostral & $+/+$ & $+1-$ \\
\hline intermediate & $+/+$ & $+/+$ \\
\hline caudal & $+/+$ & $-1-$ \\
\hline \multicolumn{3}{|c|}{ Periaqueductal gray (PAG) lateral } \\
\hline rostral & $+/+$ & $+/-$ \\
\hline intermediate & $+/+$ & $+/+$ \\
\hline caudal & $+/+$ & $-1-$ \\
\hline \multicolumn{3}{|c|}{ Principal sensory nucleus of the trigeminal (PSV) } \\
\hline ventral & $-1+$ & $-1+$ \\
\hline medial & $-1+$ & $-1-$ \\
\hline \multicolumn{3}{|c|}{ Substantia nigra, reticular part (SNr) } \\
\hline dorsolateral & $-1-$ & $+/-$ \\
\hline ventromedial & $++/-$ & $-1-$ \\
\hline
\end{tabular}

(Continued)
Table 1 | Continued

\begin{tabular}{lll}
\hline & $\begin{array}{l}\text { SCm ipsi/ } \\
\text { contra }\end{array}$ & $\begin{array}{l}\text { SCI ipsi/ } \\
\text { contra }\end{array}$ \\
\hline $\begin{array}{l}\text { SIMILAR PROJECTIONS } \\
\text { Diencephalon } \\
\text { Hypothalamus }\end{array}$ & \\
$\begin{array}{l}\text { Lateral hypothalamic area (LHA) } \\
\text { Brainstem }\end{array}$ & $+/-$ & $+/-$ \\
Locus ceruleus (LC) & $++/++$ & $+/+$ \\
$\begin{array}{l}\text { Midbrain reticular nucleus (MRN) } \\
\text { Pedunculopontine nucleus (PPN) }\end{array}$ & $+/-$ & $+/-$ \\
$\begin{array}{l}\text { SPV } \\
\text { Cerebellum }\end{array}$ & $++/+$ & $++/-$ \\
Dentate nucleus (DN) & $-/+$ & $-/+$ \\
\hline
\end{tabular}

${ }^{a}$ Counts of number of labeled cells per $0.25 \mathrm{~mm}^{2}$ and converted to a four point ordinal density measure: $0=-; 1-40=+; 41-80=++; 81-120=+++$; $120-$ more $=++++$.

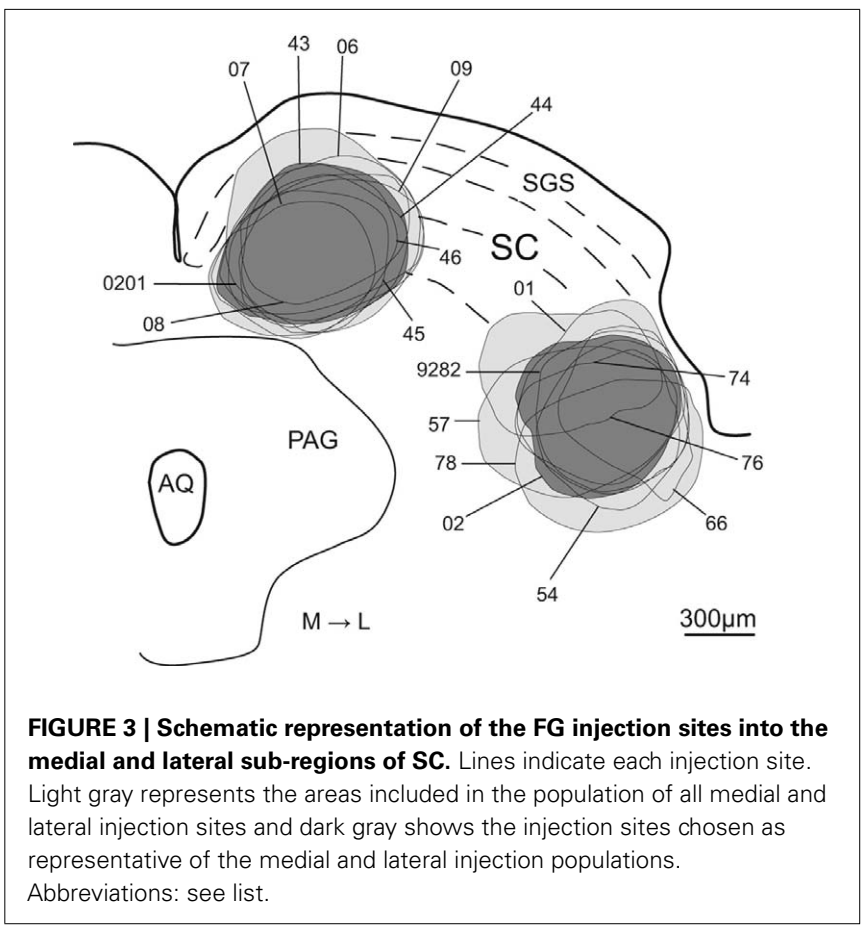

formation. Substantial numbers of retrogradely labeled neurons were found along the whole extension of the retrosplenial area (RSP; Figures 5E-J and 6C), visual area (VIS; Figures 5G-J and $6 \mathrm{C}$ ), and caudal levels of the temporal association area (TEa; Figures 5I,J). Moderate numbers of retrogradely labeled neurons were observed in the somatosensory cortex representing the lower limb and trunk (Figures 5D and 6A), the auditory area (AUD; Figures $5 \mathbf{E}-\mathbf{H}$ and $\mathbf{6 B}$ ), parietal cortex (PTL; Figures 5G-I and 6B), and rostral levels of the ectorhinal area (ECT; Figure 5E). In contrast, relatively few retrogradely labeled neurons were found in the infralimbic and pre-limbic areas (ILA, PL; Figure 5A), while in the hippocampal formation we found a moderate number of labeled neurons in the postsubiculum (Figure 5J). 


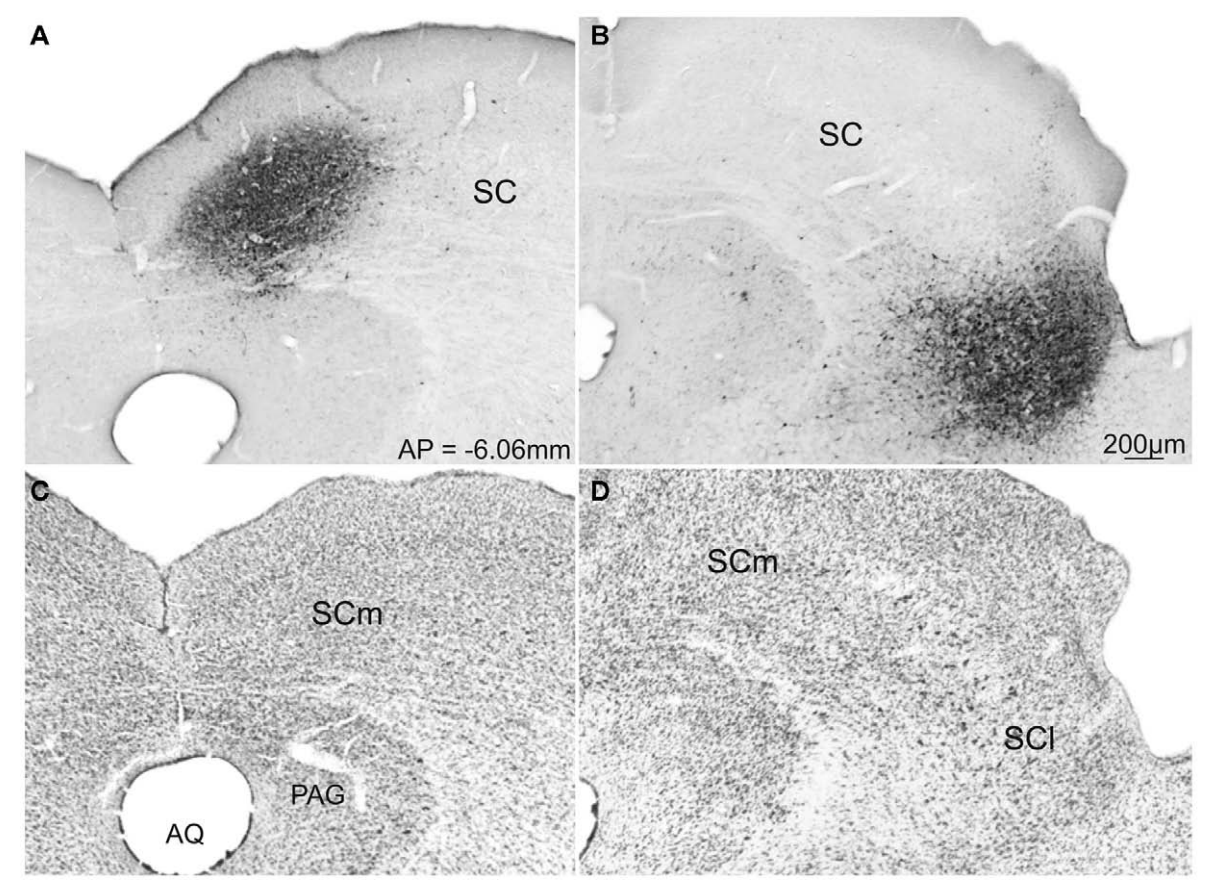

FIGURE 4 | Photomicrographs of transverse sections of the rat brain showing representative cases with FG injection into the SCm (A) and SCI (B). Respective adjacent sections show the SC cytoarchitecture stained with Nissl stain (C,D). Abbreviations: see list.

\section{Thalamus}

In the thalamus large numbers of retrogradely labeled neurons were found ipsilaterally in the ventral part of the lateral geniculate complex (LGv; Figures 5E,F and 6E) and rather less contralaterally. Moderate numbers of labeled neurons were also found ipsilaterally in the suprageniculate nucleus (SGN; Figure 5H). Small amounts of label were observed ipsilaterally in the lateral posterior nucleus of thalamus (LP; Figure 5F).

\section{Hypothalamus}

High densities of retrograde labeling were observed in the dorsomedial part of the ventromedial hypothalamic nucleus (VMH; Figures 5D,E). Densely marked neurons were also found in the dorsal premammillary hypothalamic nucleus (PMd; Figures $5 \mathbf{F}$ and 6D). Moderate numbers of labeled neurons were found contralaterally in these two structures (VMHdm and PMd).

\section{Brainstem}

In contrast to much of the retrograde labeling in the forebrain, much of the retrograde tracing in the brainstem was bilateral. The only exceptions were the nucleus prepositus and supragenual nucleus where labeled neurons were found contralaterally to the collicular injection site. At the mesencephalic levels, moderate numbers of labeled neurons were found in the precommissural nucleus (PRC; Figure 5F) while small to moderate numbers of retrogradely labeled neurons were observed in the pretectal area including the anterior, medial, and olivary pretectal nuclei (APN, MPT, OP; Figure 5F), and in the nucleus sagulum (SAG; Figure 5J). At pontine levels, moderate and large amounts of labeled neurons were observed respectively in the nucleus prepositus (PRP; Figure 5O) and the supragenual nucleus (SG; Figure $5 \mathrm{~N}$ ), while moderate numbers of labeled neurons were found in the cuneiform nucleus (CUN; Figures $5 J, \mathrm{~K}$ and $6 \mathrm{~F}$ ), laterodorsal tegmental nucleus (LDT; Figure 5K), and nucleus incertus (NI; Figure 5L).

\section{PROJECTIONS EXCLUSIVE TO THE LATERAL-APPROACH SUB-REGION OF THE SC}

The most obvious difference was that, compared to the medial deep layers of the SC, only a few afferent structures project exclusively to the lateral deep layers. Thus, a few retrogradely labeled neurons were observed in parts of the ipsilateral primary somatosensory cortex representing the upper limb and nose (Figures $\mathbf{5 B}^{\prime}$ and $\mathbf{6 G}$ ), also in the gustatory, agranular insular, and visceral areas of the isocortex (GU, AI, Figure $\left.\mathbf{5 B}^{\prime}\right)$. In the brainstem, a moderate number of retrogradely labeled neurons were found only in the contralateral parvicellular reticular nucleus (PARN; Figures $5 \mathrm{~N}^{\prime}$ and $\mathbf{6 H}$ ).

\section{TOPOGRAPHICALLY ORGANIZED PROJECTIONS TO SC}

In this section we will describe the afferent structures that project to both medial and lateral sub-regions of the deep SC, but that within the parent structure neurons retrogradely labeled from the medial and lateral SC were spatially separated. These topographically organized inputs originated from some isocortical areas, zona incerta, substantia nigra pars reticulata, and some restricted areas in the brainstem.

\section{Cerebral cortex}

In all cases where the afferent input was organized topographically, retrogradely labeled neurons were found ipsilateral 


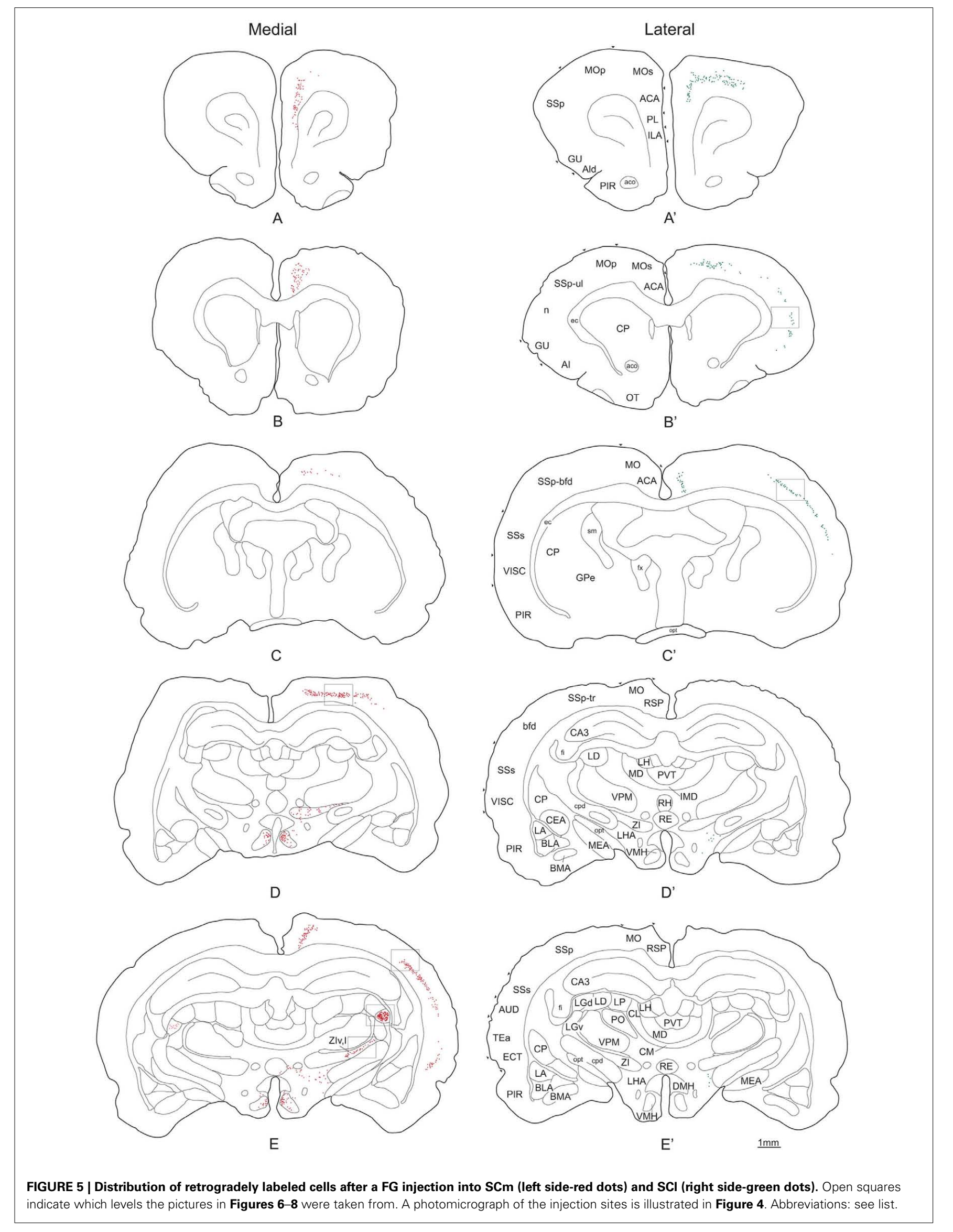



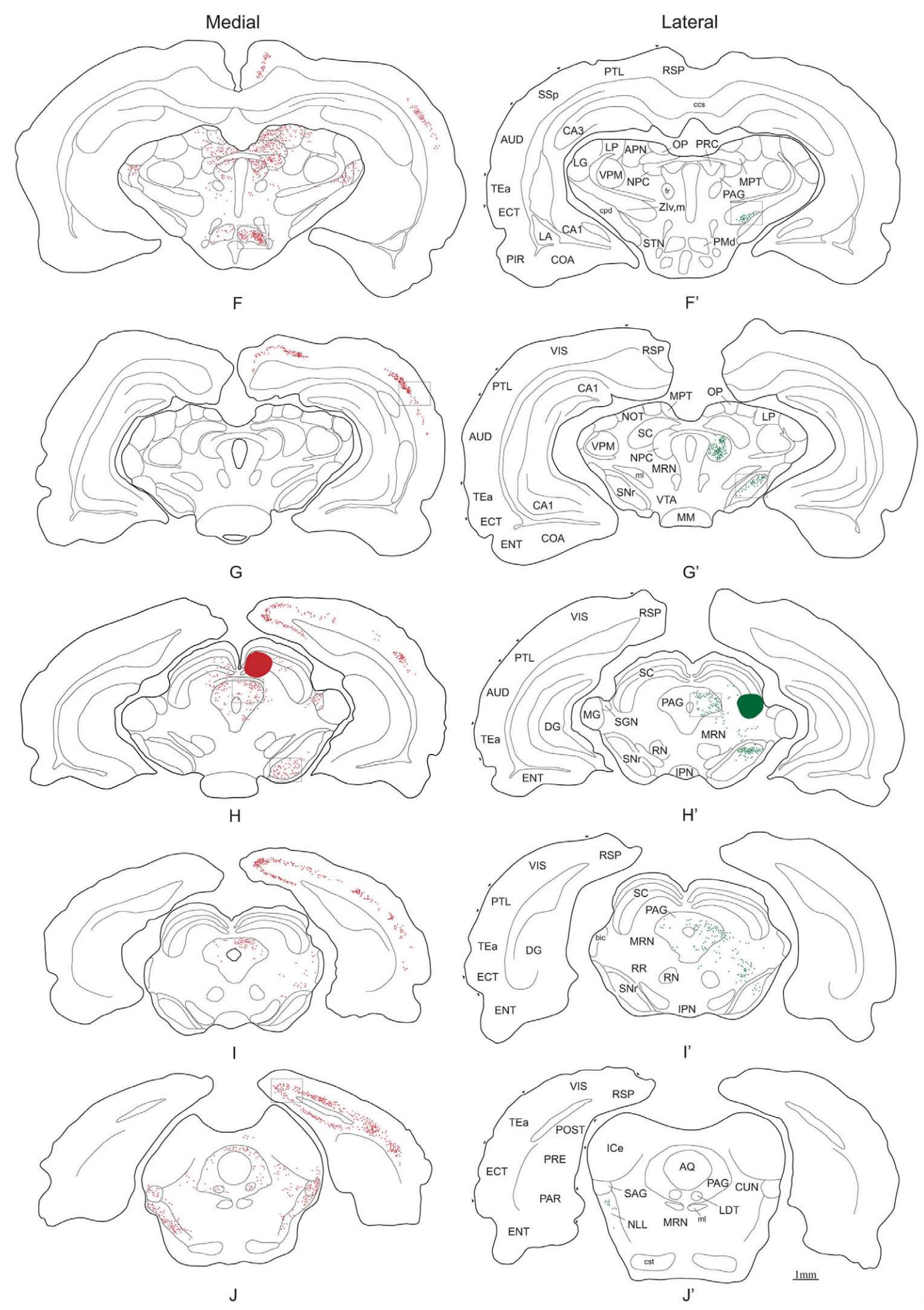

FIGURE 5 | (Continued) 


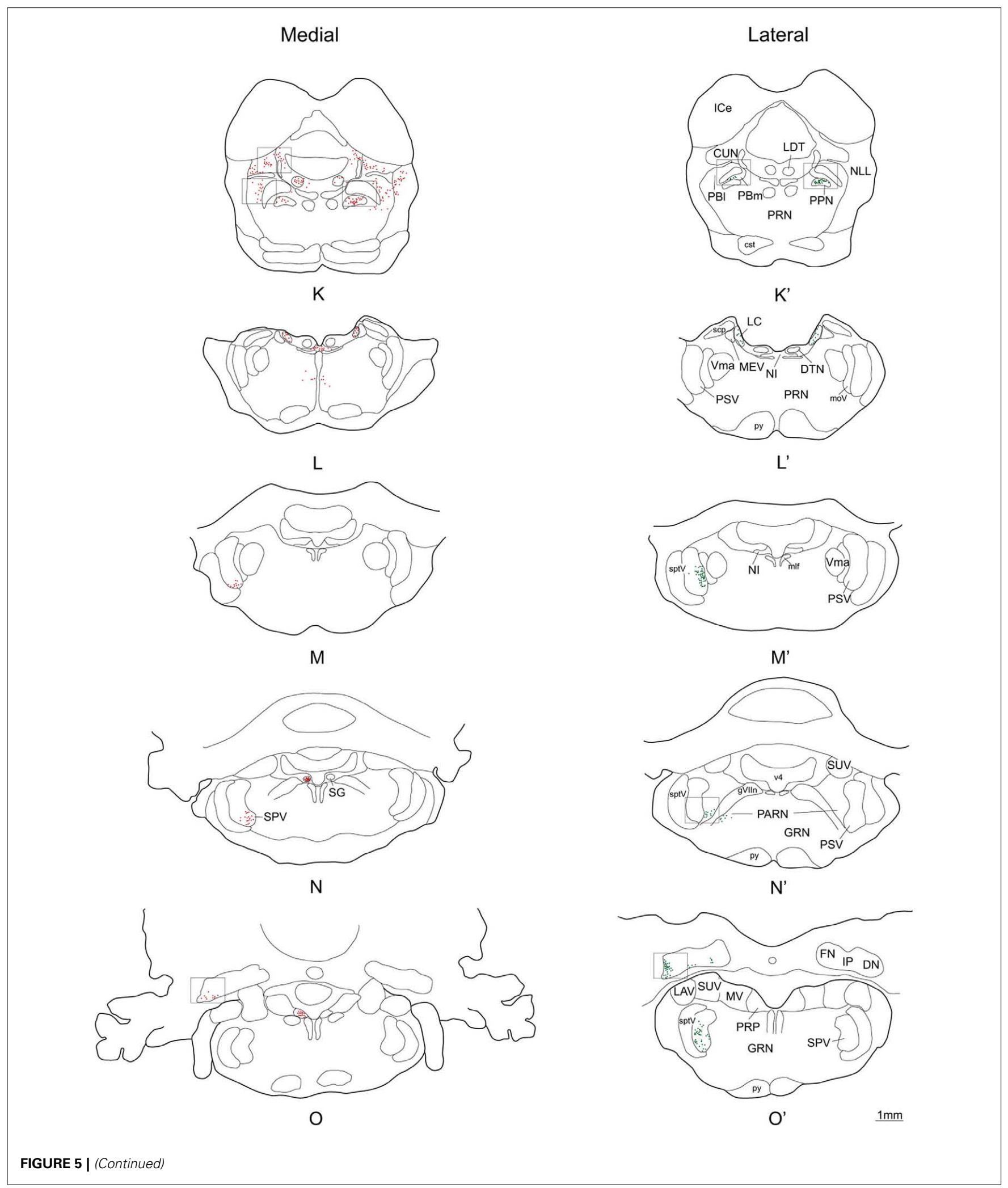

to the SC injection site. Following injections into the medial $\mathrm{SC}$, small to moderate numbers of retrograde labeled neurons were found in the caudal parts of the primary and secondary somatomotor areas (MOp, MOs; Figures 5A-C), the barrel field area (SS-bfd; Figures $5 \mathrm{E}$ and $7 \mathbf{A}$ ), and the supplemental somatosensory area (SSs; Figure 5E). In contrast, injections 

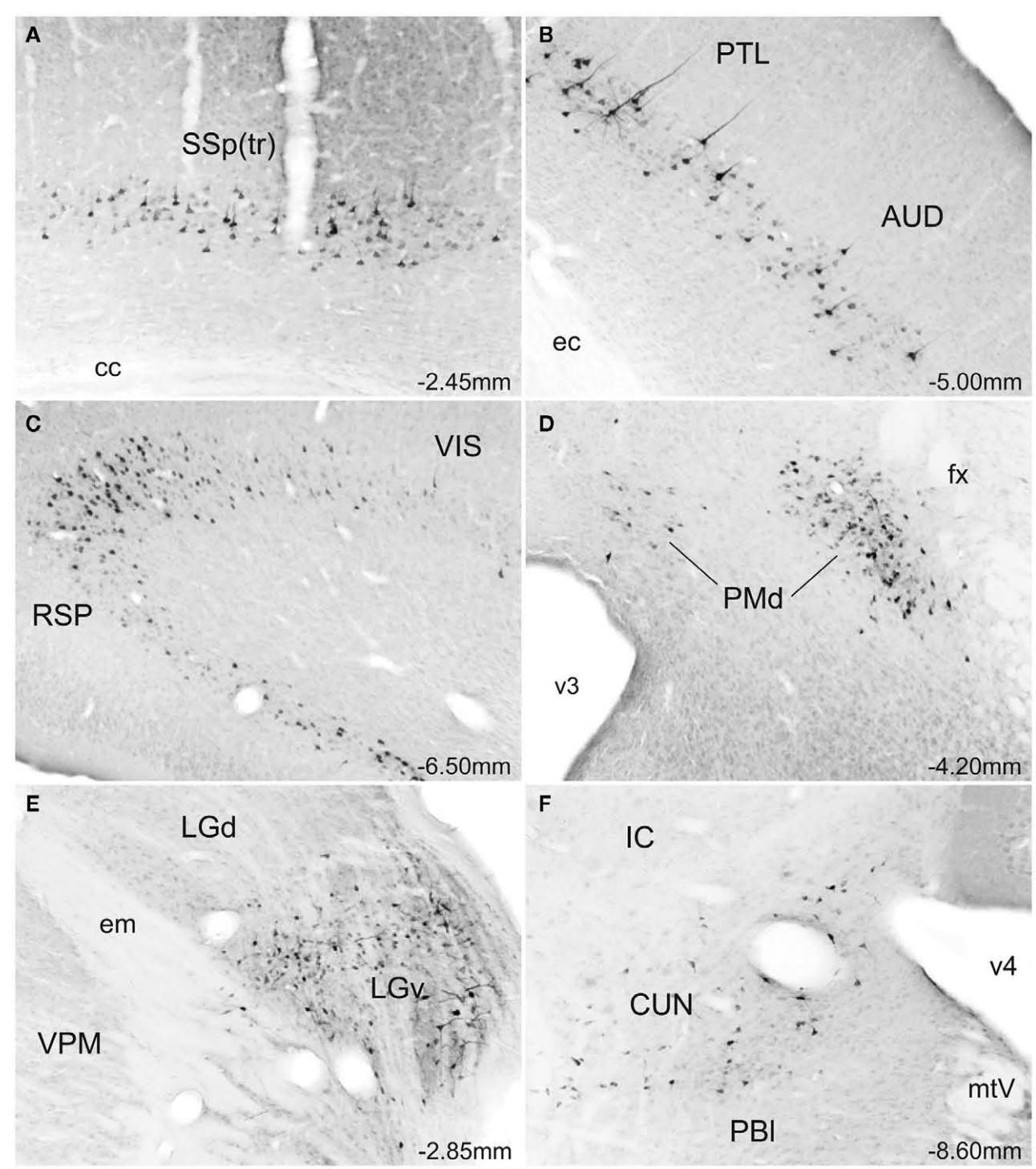

$\mathbf{F}$

G

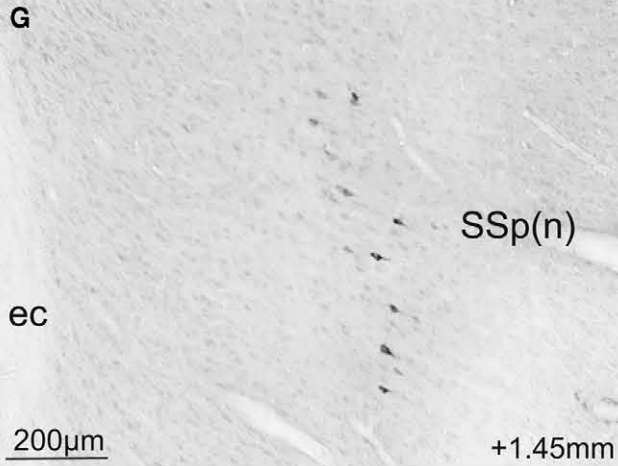

IC

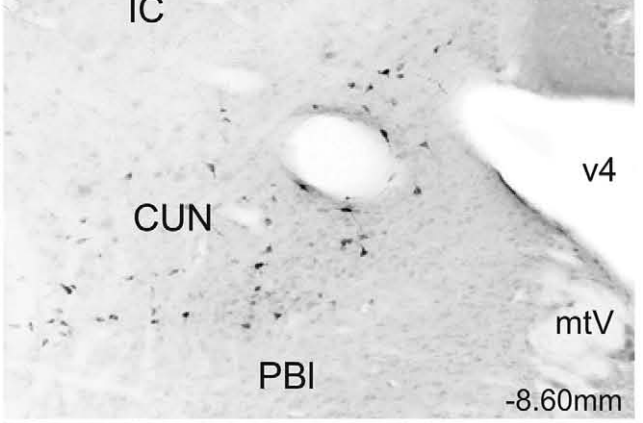

H

\section{PARN}
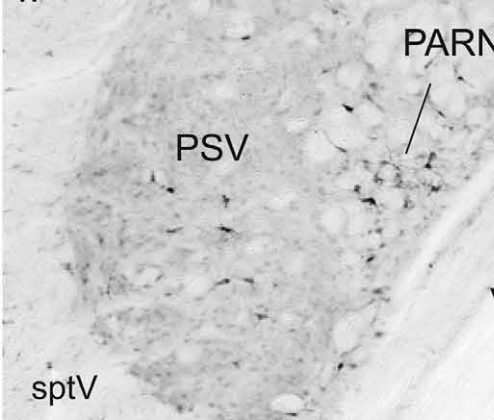

sptV

$-10.35 \mathrm{~mm}$

FIGURE 6 | Photomicrographs of transverse sections of the rat brain showing some of the areas with exclusive FG-stained cells from a rat injected into the $\mathbf{S C m}(\mathbf{A}-\mathbf{F})$ or into the $\mathbf{S C l}(\mathbf{G}, \mathrm{H})$. Abbreviations: see list.

into the lateral SC produced small to moderate amounts of retrograde labeled neurons in the rostral part of the somatomotor cortex (MOp, MOs; Figures $\mathbf{5} \mathbf{A}^{\prime}-\mathbf{C}^{\prime}$ ), the barrel field area
(SS-bfd; Figures $\mathbf{5} \mathbf{C}^{\prime}$ and $\mathbf{7 B}$ ), and the supplemental somatosensory area (SSs; Figure $\mathbf{5} \mathbf{C}^{\prime}$ ). In the cingulate cortex injections in the medial SC produced moderate numbers of retrogradely 


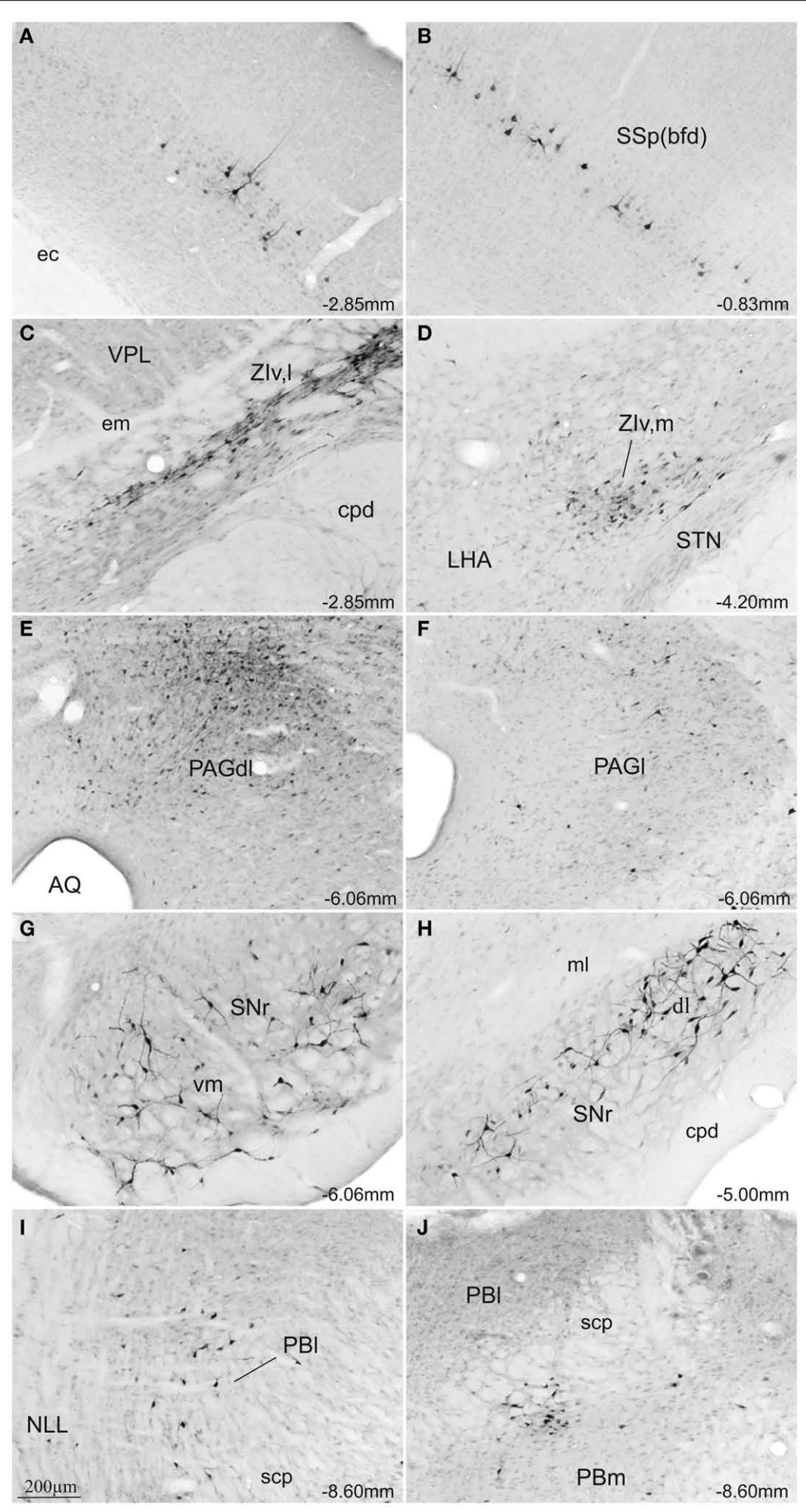

FIGURE 7 | Photomicrographs of transverse sections of the rat brain showing some of the areas with differential topography of FG-stained cells from a rat injected into the $\mathrm{SCm}(\mathrm{A}, \mathrm{C}, \mathrm{E}, \mathrm{G}, \mathrm{I})$ or into the $\mathrm{SCI}(\mathrm{B}, \mathrm{D}, \mathrm{F}, \mathrm{H}, \mathrm{J})$. Abbreviations: see list.

labeled neurons in the rostral part of the anterior cingulated area (Figures 5A,B) while similar densities of labeling were found more caudally following injections into the lateral SC (Figure 5C'). 


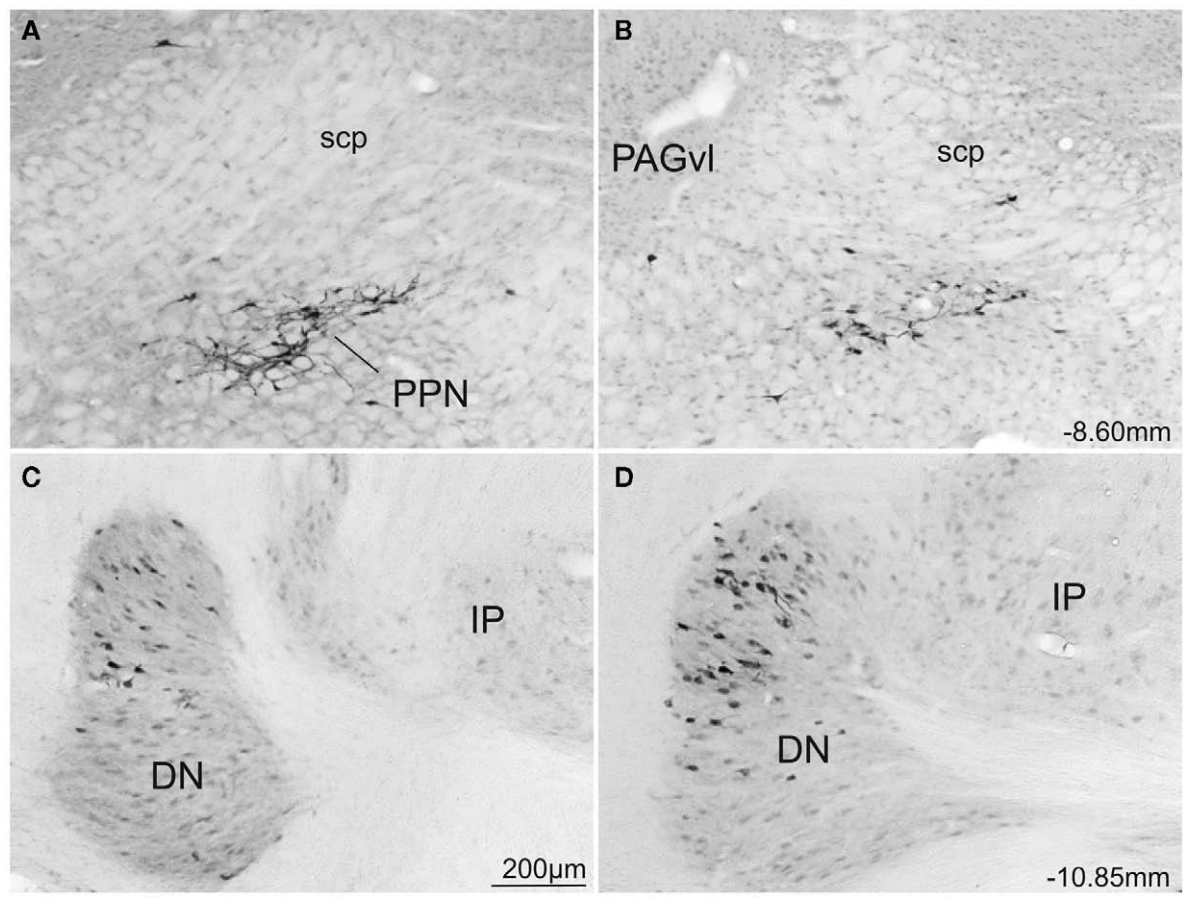

FIGURE 8 | Photomicrographs of transverse sections of the rat brain showing some of the areas with similar topography of FG-stained cells from a rat injected into the $\mathrm{SCm}(A, C)$ or into the $\mathrm{SCI}(B, D)$. Abbreviations: see list.

\section{Thalamus}

Injections into the medial SC produced moderate numbers of retrograde labeled neurons ipsilaterally in the lateral parts of rostral ventral zona incerta (ZIv,l; Figures 5E and 7C). In cases receiving injections into the lateral SC, moderate levels of retrograde labeling was confined to the medial parts of caudal ventral zona incerta (ZIv,m; Figures $\mathbf{5 F ^ { \prime }}$ and $\mathbf{7 D}$ ).

\section{Brainstem}

In the pretectal area, following injections into the medial SC, retrograde labeling was found bilaterally in the rostral part of the nucleus of the posterior commissure (moderate amounts in the ipsilateral and small amounts in the contralateral NPC; NPC; Figure 5F). In contrast, moderate amounts of retrograde label was observed only ipsilaterally in the caudal parts of the nucleus of the posterior commissure after injections in the lateral SC (NCP; Figure $5 \mathbf{F}^{\prime}$ ).

At the level of the mesencephalon, topographically organized retrograde labeling was found in the ipsilateral substantia nigra pars reticulata. Injections into the medial SC produced moderate numbers of labeled neurons ventromedially ( $\mathrm{SNr}$; Figures $\mathbf{5 H}$ and 7G) while moderate labeling following lateral injections was located dorsolaterally ( $\mathrm{SNr}$; Figures $5 \mathbf{G}^{\prime}-\mathbf{I}^{\prime}$ and $\mathbf{7 H}$ ). In the periaqueductal gray medial injections into the $\mathrm{SC}$ were associated with moderate retrograde labeling distributed bilaterally along the dorsolateral column (PAGdl; Figures 5H-J and 7E), while fewer numbers of labeled cells were observed ipsilaterally in the lateral column (PAGl; Figures 5H-J and 7E). When injections were placed in the lateral SC moderate numbers of retrogradely labeled neurons were found ipsilaterally mainly in the lateral and dorsolateral columns at rostral and intermediate levels of the periaqueductal gray (Figures $\mathbf{5} \mathbf{H}^{\prime}, \mathbf{I}^{\prime}$ and $\mathbf{7 F}$ ). Contralateral periaqueductal gray was only sparsely labeled by lateral SC injections.

In the nucleus of the lateral lemniscus, medial injections in the SC resulted in moderate bilateral labeling of both dorsal and ventral parts of the structure (NLL; Figures 5J). Lateral SC injections were associated with a sparser distribution, exclusively contralateral, and confined to the dorsomedial part of the nucleus (NLL; Figure $5 \mathbf{J}^{\prime}$ ). In the rostrolateral parabrachial area, medial injections were associated with sparse bilateral labeling ( $\mathrm{PBl}$; Figures $5 \mathrm{~K}$ and 7I), while labeling following lateral SC injections was located contralaterally in the medial subdivision of the parabrachial area, (PBm; Figures $\mathbf{5} \mathbf{K}^{\prime}$ and $\mathbf{7} \mathbf{J}$ ).

Finally, after medial SC injections, moderate numbers of retrogradely labeled cells were observed contralaterally in the ventral part of the principal sensory nucleus of the trigeminal complex (PSV; Figure 5M). In contrast, only the medial part of the principal sensory nucleus of the trigeminal complex was labeled at more rostral levels (PSV; Figure $\mathbf{5} \mathbf{M}^{\prime}$ ) after the lateral SC injections.

\section{STRUCTURES WITH OVERLAPPING PROJECTIONS TO MEDIAL AND LATERAL SUB-REGIONS OF THE SC}

Only the lateral hypothalamic area and a very few structures in the brainstem contained a similar distribution of retrogradely labeled neurons following injections into medial or lateral sub-regions of the deep SC. Thus, the lateral hypothalamic area had only scattered labeled neurons located adjacent to the cerebellar peduncle at the tuberal level (LHA; Figures $5 \mathbf{E}, \mathbf{D}^{\prime}, \mathbf{E}^{\prime}$ ). Moreover, moderate 
amounts of label with a similar spatial distribution were observed in the pedunculopontine nucleus (bilaterally for medial injections and ipsilaterally for lateral injections; PPN; Figures $\mathbf{5 K}, \mathbf{K}^{\prime}$ and 8A,B). Also following both medial and lateral SC injections, moderate numbers of labeled neurons were observed bilaterally in the locus ceruleus (LC; Figures $5 \mathbf{L}, \mathbf{L}^{\prime}$ ), and contralaterally in the cerebellar dentate nucleus (DN; Figures 50,0' and 8C,D). Finally, small numbers of retrograde labeled neurons were found ipsilaterally in the midbrain reticular nucleus including the retrorubral area $\left(\mathrm{MRN}, \mathrm{RR}\right.$; Figures $\left.\mathbf{5 H}, \mathbf{I}, \mathbf{H}^{\prime}, \mathbf{I}^{\prime}\right)$, and contralaterally in the spinal nucleus of trigeminal (SPV; Figures $5 \mathrm{~N}, \mathbf{O}^{\prime}$, again following injections into both medial and lateral SC.

\section{DISCUSSION \\ MAIN FINDINGS}

In this study we exploited the regional distribution of function in the SC (medial-defense; lateral-appetitive/approach) to identify neural structures that may contribute differentially to approach and avoidance responses. Our main findings were: (i) there was very little overlap in the afferent control of medial and lateral subregions of the rodent SC. (ii) Significantly more neural structures exercise afferent control over defense compared with approach associated regions of the SC. Thus, numerous sites in different parts of the cerebral cortex, visual thalamus, limbic regions, pre-tectum, and brainstem contained retrogradely labeled neurons only after injections into the medial SC. (iii) In structures that send projections to both medial and lateral SC, the majority (several cortical regions, zona incerta, pre-tectum, periaqueductal gray, substantia nigra pars reticulata, the parabrachial area, and principal sensory trigeminal nucleus) contained topographically organized retrograde labeling with little or no spatial overlap. (iv) Comparatively few structures (LC, retrorubral area, pedunculopontine nucleus, spinal sensory trigeminal nucleus, and cerebellum) contained overlapping distributions of retrogradely labeled neurons following injections into medial and lateral SC. A summary of these results is presented in Figure 9. We will discuss

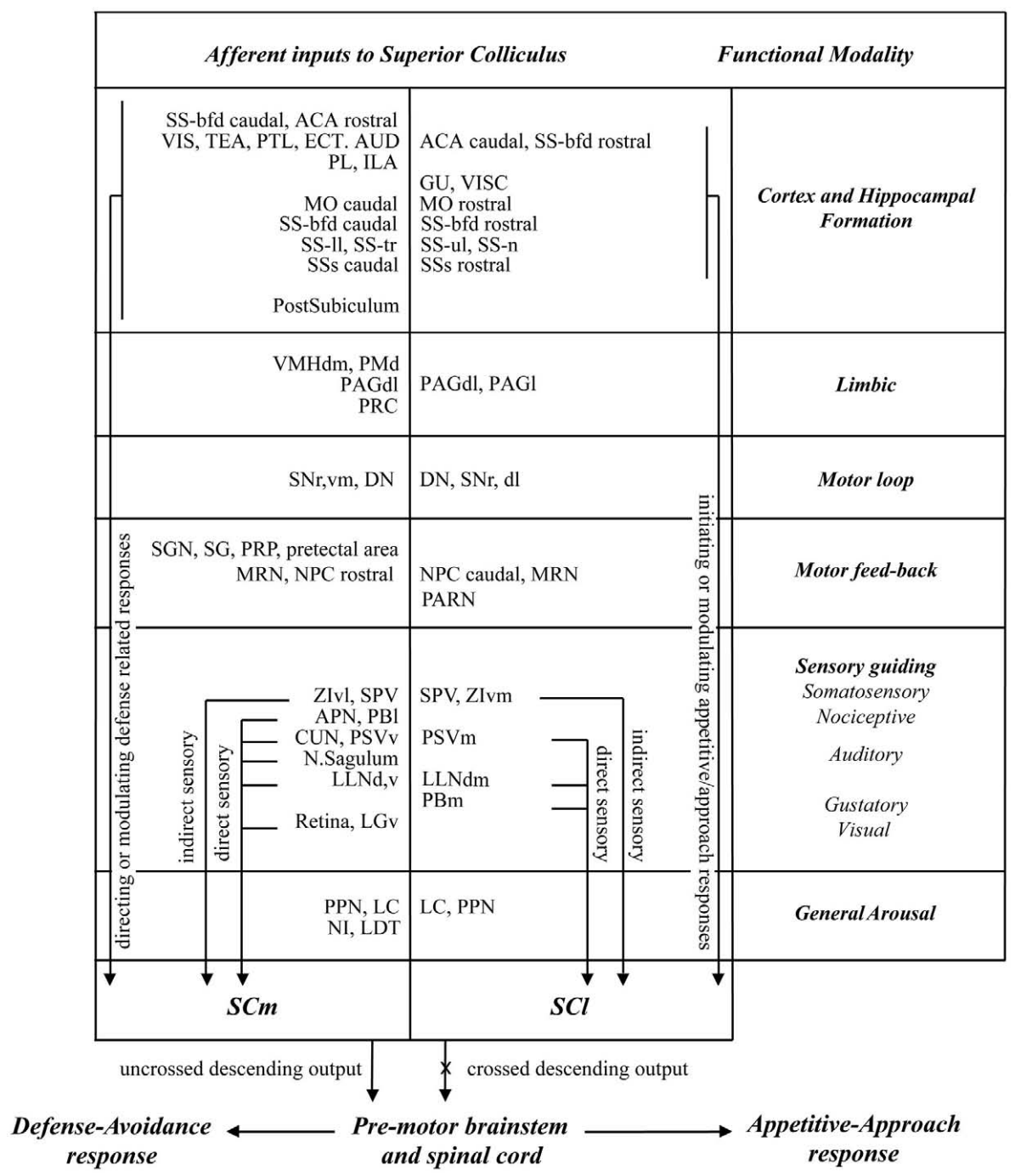

FIGURE 9 | Summary of the functional inputs to sub-regions of the rat SC associated with approach and defense responses. 
these observations, first in terms of technical issues that may influence their interpretation. We will then relate them to previous investigations of afferent SC anatomy, and conclude by considering their functional implications.

\section{TECHNICAL CONSIDERATIONS}

The retrograde anatomical tracing technique was used to provide a general overview of the sources of input to the separate functionally defined regions of the SC, also, a relative estimate of the potential importance among the range of afferent projections. We used iontophoretic application of the tracer Fluoro-Gold because of its sensitivity as a retrograde tracer. In particular, it provides discrete injection sites with minimal uptake of the tracer by nonterminating fibers of passage (Brog et al., 1993). Our use of this single highly sensitive tracer was to maximize the reliability of between case comparisons. That is, the variability associated with uptake and transport is likely to be more consistent for a single anatomical tracer, as opposed to when a range of different anatomical tracers are used. Moreover, given there was so little overlap in the afferent projections to the medial and lateral SC, we considered the use of double label techniques unnecessary. Our use of a maximum density measure of retrograde tracing provides an estimate of the potential density of terminating projections associated with medial and lateral injection sites (Table 1). Clearly, this measure can be used only as a guide as it takes no account the relative volumes of afferent structures, the overall numbers and distribution of labeled neurons they contain. Neither can the density measure accommodate slight differences in the sizes of the two injections, differences in the patterns of terminating fibers, either in terms of the degree of terminal branching, or the locations where afferent terminals make contact with targeted neurons - distal dendrites or proximal neuronal cell bodies. A finer resolution of these issues awaits further investigation.

\section{RELATIONSHIP TO PREVIOUS INVESTIGATIONS}

With possibly one exception (projections from the postsubicular region), all the afferent structures we identified in the present study have been described by others previously (Wise and Jones, 1977; Killackey and Erzurumlu, 1981; Roldán and Reinoso-Suárez, 1981; Huerta et al., 1983; Cadusseau and Roger, 1985; Tanaka et al., 1985; Vertes et al., 1986; Henkel and Schneiderman, 1988; Rhoades et al., 1989; Sesack et al., 1989; Appell and Behan, 1990; Cornwall et al., 1990; Canteras and Swanson, 1992; Ohtsuki et al., 1992; Redgrave et al., 1992; Wiberg, 1992; Waterhouse et al., 1993; Canteras et al., 1994; Klooster et al., 1995; Krauthamer et al., 1995; Kolmac et al., 1998; Canteras and Goto, 1999; Garcia Del Caño et al., 2000; Moore et al., 2000; Olucha-Bordonau et al., 2003; Wyss and Sripanidkulchai, 2003; Kimura et al., 2004; Sefton et al., 2004; Kelly et al., 2009; Alloway et al., 2010).

The importance of the current investigation is the finding that, with very few exceptions, afferent structures, or sub-regions within afferent structures, project to either the medial, or lateral deep $\mathrm{SC}$, but not to both. In previous anatomical studies in rodents there was a strong, entirely rational tendency to place injections of retrograde anatomical tracer centrally within the SC, both in terms of rostro-caudal and medio-lateral placement. Because these injections encroached into both medial and lateral sectors of the SC, previous investigations were able to identify most afferent structures, but missed the point that the medial-defense and lateral-approach territories of the rodent SC receive almost entirely from segregated populations of afferent neurons. The possibility that SC approach and defense systems receive inputs from anatomically separate systems will have important implications for the regulation of initial approach and avoidance responses elicited by sudden sensory events. However, as noted in the Introduction, functional segregation of the SC is likely to be a particular feature of animals whose predators and prey consistently originate in different parts of the visual field. Consequently, we would expect the segregation of afferents, according to targeted regions in the $\mathrm{SC}$, to be less clear in species whose predators and/or prey frequently appear in the upper or lower visual fields (Swanson et al., 1974; Updyke, 1977; Roldán and Reinoso-Suárez, 1981; Huerta and Harting, 1982; Kawakura et al., 1982; Lynch et al., 1985; Room et al., 1985; Henkel and Schneiderman, 1988; Meredith and Clemo, 1989; Harting et al., 1992; Buchanan et al., 1994; May et al., 1997; Klop et al., 2005; May, 2006; Aronoff et al., 2010; Manger et al., 2010).

\section{FUNCTIONAL IMPLICATIONS}

To understand the variety of afferent projections to the SC identified in this and other reports (Wise and Jones, 1977; Kawakura et al., 1982; Druga and Syka, 1984; Cadusseau and Roger, 1985; Tanaka et al., 1985; Meredith and Clemo, 1989; Buchanan et al., 1994; Ndiaye et al., 2002; Olucha-Bordonau et al., 2003; Klop et al., 2005; Manger et al., 2010), it is important to consider, briefly, the evolutionary history of the SC and the requirements for organizing effective defense and approach behaviors. The SC is an evolutionarily ancient sensorimotor structure found in the midbrain of the earliest vertebrates (Wurtz and Albano, 1980; Sparks, 1986; Dean et al., 1989; Stein and Meredith, 1993). With relatively minor modifications, it has been retained in a largely conserved form and is present in the dorsal midbrain of all modern mammals (Gaither and Stein, 1979; Stein, 1981, 1984; May, 2006). The need to defend against predators and approach sources of sustenance, mates, and in some cases offspring, are, however, also survival imperatives for primitive vertebrates that lack the flexibility conferred by the more evolutionarily recent expansion of the cerebral cortex. Consequently, there is evidence that the SC plays a prominent role in approach and avoidance functions of primitive species (Saitoh et al., 2007). We will therefore, first consider the sub-cortical afferent connections of the SC which are likely to have enabled the SC to perform effective approach and defensive functions in evolutionarily primitive vertebrates that lack a developed cerebral cortex.

\section{Sub-cortical afferents of the SC}

Direct sensory. As an ancient sensorimotor structure, the SC receives a range of relatively direct sub-cortical multisensory inputs that have the capacity to guide acquisitive/approach or defensive/withdrawal responses. These multisensory inputs include direct visual projections from retina and the lateral geniculate nucleus of the thalamus (Figures 5E,F; Nagata and Hayashi, 1984; Born and Schmidt, 2008), somatosensory, and nociceptive inputs from the trigeminal nuclei (Figures $\mathbf{5} \mathbf{M}, \mathbf{N}, \mathbf{M}^{\prime}, \mathbf{O}^{\prime}$ ), 
parabrachial nucleus (Figures 5K, $\mathbf{K}$; ; Killackey and Erzurumlu, 1981; Ricardo, 1981; Huerta et al., 1983; May, 2006), and cuneiform nucleus (Carlson et al., 2004), auditory input from nucleus of the lateral lemniscus and nucleus sagulum (Figures 5J,J' ; Henkel and Schneiderman, 1988; Kelly et al., 1998, 2009; Bajo et al., 1999). Among these sensory afferents it appears that vibrissae-related signals from the oral trigeminal nucleus are directed preferentially to the rostrolateral enlargement of the SC deep layers where they play a critical role in approach movements such as those associated with predatory hunting (Figure 50'; Furigo et al., 2010; Favaro et al., 2011). On the other hand, nociceptive somatosensory input from the sensory trigeminal nucleus (Figures $5 \mathrm{M}, \mathbf{N}$; Páli et al., 2002; Sokov et al., 2011) is directed to the medial SC, where it would be in a position to evoke defensive withdrawal movements. Alternatively, nociceptive input from lower parts of the body are relayed via the lateral parabrachial area (Bernard and Besson, 1990; Bernard et al., 1994; Bester et al., 1995; Bon et al., 1996; Menendez et al., 1996; Gauriau and Bernard, 2002; Coizet et al., 2006) and cuneiform nuclei (Carlson et al., 2004) to the medial SC. Moreover, nociceptive somatosensory input from sensory trigeminal nucleus is conveyed to the lateral SC (Figure $\mathbf{5} \mathbf{M}^{\prime}$ ), where they can guide head and mouth movements to a source of pain (Wang and Redgrave, 1997).

Indirect sensory. Parts of the limbic system including the amygdala are responsible for associating predictive neutral stimuli with unconditioned appetitive or aversive events so the neutral stimuli acquire the ability to evoke conditioned approach or defensive responses - Pavlovian conditioning (Takahashi et al., 2008). While there is no direct output from amygdala to the SC, several other limbic structures that receive inputs from the amygdala contained significant amounts of retrograde labeling from our injections into the medial SC, e.g., the ventromedial hypothalamic nucleus (Canteras et al., 1994) and dorsal premammillary nucleus (Canteras and Swanson, 1992), which are known to be part of the medial hypothalamic defense circuitry (Figures 5D-F), and periaqueductal gray (Figures 5H-J; Wiberg, 1992) in addition to the precommissural nucleus (Figure 5F), which is viewed as the rostral part of periaqueductal gray. Input from the hypothalamus was directed largely to the medial SC and therefore likely to be associated mainly with defensive responding. On the other hand, the periaqueductal gray has efferent contact with both medial and lateral SC with differential inputs from the dorsolateral and lateral columns respectively (Figures $\mathbf{5 H}-\mathbf{J}, \mathbf{H}^{\prime}, \mathbf{I}^{\prime}$; Wiberg, 1992). It is therefore possible that the lateral SC, with its ability to direct the eyes, head, and body toward external stimuli, could play an important role when defensive strategy switches from escape/avoidance to attack (Carvalho-Netto et al., 2006).

Indirect sensory-related signals may also originate from the zona incerta (Figures 5D,E,F'; Simpson et al., 2008). Sensory input from the zona incerta to the SC is organized topographically so that vibrissal-related regions of the ventral zona incerta (caudomedial Figure $5 \mathbf{F}^{\prime}$ ) project to the lateral deep layers of the $\mathrm{SC}$, while the medial SC receives input from body-related areas of ventral zona incerta (rostrolateral - Figures 5D,E; Nicolelis et al., 1992). However, since the neurons that comprise the incerto-tectal projection are largely GABAergic (Ficalora and Mize, 1989; Appell and Behan,
1990; Nicolelis et al., 1992) the nature and circumstances of the modulation imposed on the SC by this structure is not clear.

Motor feedback. Behavioral output of the SC is mediated via the crossed (approach) or the uncrossed (defense) descending projections. Both efferent projections connect the SC with pre-motor and pre-cerebellar nuclei in the brainstem and upper spinal cord (King et al., 1996; Shehab et al., 2007). The SC receives input from several of these efferent relays through which the SC exercises control over the eyes, head, and body. These include the pretectal nuclei (Figure 5F; Trejo and Cicerone, 1984; Cadusseau and Roger, 1985; Klooster et al., 1995), nucleus of the posterior commissure (Figures 5F,G'; Huerta and Harting, 1982), periaqueductal gray (Figures $\mathbf{5} \mathbf{H}-\mathbf{J}, \mathbf{H}^{\prime}, \mathbf{I}^{\prime}$; Wiberg, 1992), the mesencephalic reticular nucleus (Figures 5H-J, $\mathbf{H}^{\prime}, \mathbf{I}^{\prime}$; Vertes et al., 1986), the cuneiform nucleus (Figures 5J,K; Appell and Behan, 1990), pontine reticular formation (Figure $\mathbf{5 L}$ ), the PARN (Figure $\mathbf{5} \mathbf{N}^{\prime}$; Shammah-Lagnado et al., 1992), supragenual nucleus, and nucleus prepositus (Figure 5N,O; Ohtsuki et al., 1992; Corvisier and Hardy, 1993; Klop et al., 2005). Apart from the PARN which, is a major pre-motor region responsible for generating oral responses (Li et al., 1995, 1996) and sends information back exclusively to the lateral SC, most of the other pre-motor structures containing retrogradely labeled neurons provide feedback primarily to the medial SC.

Basal ganglia and cerebellar loops. It is increasingly clear that most of the brain's sensorimotor, cognitive, and affective structures contribute to looped architectures involving both the basal ganglia and cerebellum. The SC is no exception. It is therefore of interest that both the basal ganglia and cerebellum have evolutionary histories similar to that of the SC, i.e., they all pre-date the evolutionary expansion of the cerebral cortex by several hundred million years (Dillon, 1962; Gaither and Stein, 1979; Stein, 1981; Stephenson-Jones et al., 2011). This suggests that, to generate appropriate defensive or approach/acquisitive behavior, the SC is reliant on appropriate interactions with both the basal ganglia and cerebellum. The cerebellar input to the SC may be required to generate precise signals ensuring the control of the metrics of motor output like the generation of vertical eye movements (Chubb and Fuchs, 1982), head rotation, and saccadic-movements (Gruart and Delgado-García, 1994). However, it is interesting that, whatever function is performed by the loops involving the SC and cerebellum, it seems that the required cerebellar modulation of appetitive and defensive functions can be served by neurons with overlapping distributions in the deep cerebellar nuclei (Figures 50,0'; Roldán and Reinoso-Suárez, 1981).

A rather different computational problem arises from the fact that the spatially organized multisensory maps in the SC can represent multiple external stimuli, simultaneously. Which stimulus should be allowed to guide behavioral output and should it be approached or avoided? We have argued previously (Redgrave et al., 1999), that the looped architecture connecting the SC with the basal ganglia could provide an effective solution to such problems of "selection" via a mechanism of selective disinhibition within the nigrotectal projection. However, to "disinhibit" either defense or approach responses from the SC, the basal ganglia 
would need to have segregated contacts with both the medial and lateral SC. This would be provided for by the topographical organization of the nigrotectal projection observed in the present investigation in which the medial SC receives exclusively from ventromedial substantia nigra pars reticulata while input to the lateral SC originates exclusively from the dorsolateral part of pars reticulata (Figures 5H,G'-I' ; Redgrave et al., 1992).

General arousal. The SC has inputs from several general modulatory system involving cholinergic - pedunculopontine nucleus and laterodorsal tegmental nucleus (Figures 5K,K'; Satoh and Fibiger, 1986; Cornwall et al., 1990; Krauthamer et al., 1995), noradrenergic - LC (Figures 5L,L' ; Waterhouse et al., 1993) as well as dopaminergic cell groups - retrorubral area (Figures 5I,I' ; Vertes et al., 1986; Vertes and Martin, 1988). The highly divergent nature of these projections suggests they are likely to exercise some form of general modulatory control over the appetitive and defensive functions of the SC (Scarnati and Florio, 1997; Balatoni and Detari, 2003).

\section{Cortical afferents of the SC}

For most of the evolutionary history of vertebrates, the initiation of approach and defense-related movements by the SC was supported in large part by equally ancient sub-cortical structures. However, approximately 60 million years ago marked the beginning of a dramatic expansion of the cerebral cortex (Kass, 1995, 2004, 2011; Montagnini and Treves, 2003). The increase in computing power that this expansion afforded enabled the development of sophisticated sensory, cognitive, affective, and motivational competences. However, from the pattern of anatomical connections observed in the present study it appears that, to implement approach or defensive responses guided by cortically based signal processing, efferent cortical projections were directed to the functionally relevant regions of the SC where the necessary connections with brainstem motor mechanisms were already in place to regulate the required movements. Interestingly, the non-overlapping pattern of connections to the medial and lateral sub-regions of the SC from sub-cortical sites is mirrored by the inputs from the different regions of cerebral cortex. Thus, the areas of cerebral cortex projecting to the lateral deep SC layers were barrel field cortex and secondary somatosensory cortex (Figure 5C'; Sesack et al., 1989; Vaudano et al., 1991; Alloway et al., 2010), whisker motor cortex (Figures 5. $\mathbf{A}^{\prime}, \mathbf{B}^{\prime}$; Alloway et al., 2010), gustatory and visceral cortex (Figure 5B' ${ }^{\prime}$; Reep et al., 1987; May, 2006), and caudal parts of anterior cingulate cortex (Figure 5C'; Sesack et al., 1989; Hurley

\section{REFERENCES}

Alloway, K. D., Smith, J. B., and Beauchemin, K. J. (2010). Quantitative analysis of the bilateral brainstem projections from the whisker and forepaw regions in rat primary motor cortex. J. Comp. Neurol. 518, 4546-4566.

Appell, P. P., and Behan, M. (1990). Sources of subcortical GABAergic projections to the superior colliculus in the cat. J. Comp. Neurol. 302, 143-158.

et al., 1991; Wyss and Sripanidkulchai, 2003). These observations suggest these cortical regions are associated with initiating or modulating appetitive approach. On the other hand, cortical input to the medial SC was more functionally diverse, including projections from visual cortex (Figures 5G-J; Updyke, 1977; Harvey and Worthington, 1990), retrosplenial cortex (Figures 5E-J; Van Groen and Wyss, 1992; Garcia Del Caño et al., 2000), temporal associative area (Figures 5I,J; Arnault and Roger, 1990; Vaudano et al., 1991), somatosensory cortex (Figures 5D,E; Hoffer et al., 2005; Lee and Kim, 2012), auditory area (Figures 5E-H; Druga and Syka, 1984; Arnault and Roger, 1990), parietal cortex (Figures 5G-I; Glickstein, 2003), rostral levels of ectorhinal cortex (Figure 5E; McIntyre et al., 1996), and anterior cingulated area (Figure 5A; Sesack et al., 1989; Hurley et al., 1991; Wyss and Sripanidkulchai, 2003) and, infralimbic and pre-limbic areas of frontal cortex (Figure 5A; Leichnetz and Gonzalo-Ruiz, 1987; Buchanan et al., 1994). Given that rodents are comparatively small and the prey of many larger animals, perhaps it is not surprising that more diverse computing power afforded by the cerebral cortex is given over to directing or modulating defense-related responses, possibly by commandeering the medial SC and its connections with the brainstem.

In summary, the present study exploited the functional segregation that is present in the SC of rodents to identify afferent structures that can modulate approach and defense-related responses mediated via the SC's efferent connections to the brainstem. The principal finding was that, with relatively few exceptions, there was little overlap in the afferent projections to the medial (defense) and lateral (approach) deep layers of the rodent SC. While the degree of afferent segregation may also be present in other mammals, it is likely to be more difficult to detect in species whose predators and prey can appear unexpectedly from any direction. In these species, approach- and defense-related efferent neurons projecting to the brainstem are likely to be distributed more evenly across the SC's spatial maps.

\section{ACKNOWLEDGMENTS}

This research was supported by grants from Fundação de Amparo à Pesquisa do Estado de São Paulo (FAPESP, no. 06/03655-4) and Fundação Apoio ao Ensino e Pesquisa e Assistência Hospital das Clínicas da Faculdade de Medicina de Ribeirão Preto awarded to Eliane Comoli in addition to BBSRC (BB/D019648/1) and Wellcome Trust (080943 and 091409) grants awarded to Peter Redgrave and Paul G. Overton. Plínio Das Neves Favaro received FAPESP fellowship.

(1999). Topographic organization of the dorsal nucleus of the lateral lemniscus in the cat. J. Comp. Neurol. 407, 349-366.

Balatoni, B., and Detari, L. (2003). EEG related neuronal activity in the pedunculopontine tegmental nucleus of urethane anaesthetized rats. Brain Res. 959, 304-311.

Bernard, J. F., and Besson, J. M. (1990). The spino(trigemino) pontoamygdaloid pathway: electrophysiological evidence for an involvement in pain processes. J. Neurophysiol. 63, 473-490.

Bernard, J. F., Huang, G. F., and Besson, J. M. (1994). The parabrachial area: electrophysiological evidence for an involvement in visceral nociceptive processes. J. Neurophysiol. 71, 1646-1660.

Bester, H., Menendez, L., Besson, J. M., and Bernard, J. F. (1995). Spino (trigemino) parabrachiohypothalamic pathway: electrophysiological evidence for an involvement in 
pain processes. J. Neurophysiol. 73, 568-585.

Billington, J., Wilkie, R. M., Field, D. T., and Wann, J. P. (2011). Neural processing of imminent collision in humans. Proc. Biol. Sci. 278, 1476-1481.

Bon, K., Lantéri-Minet, M., de Pommery, J., Michiels, J. F., and Menétrey, D. (1996). Cyclophosphamide cystitis as a model of visceral pain in rats. A survey of hindbrain structures involved in visceroception and nociception using the expression of c-Fos and Krox-24 proteins. Exp. Brain Res. 108, 404-416.

Born, G., and Schmidt, M. (2008). A reciprocal connection between the ventral lateral geniculate nucleus and the pretectal nuclear complex and the superior colliculus: an in vitro characterization in the rat. Vis. Neurosci. 25, 39-51.

Brog, J. S., Salyapongse, A., Deutch, A. Y., and Zahm, D. S. (1993). The patterns of afferent innervation of the core and shell in the "accumbens" part of the rat ventral striatum: immunohistochemical detection of retrogradely transported fluoro-gold. J. Comp. Neurol. 338, 255-278.

Buchanan, S. L., Thompson, R. H., Maxwell, B. L., and Powell, D. A. (1994). Efferent connections of the medial prefrontal cortex in the rabbit. Exp. Brain Res. 100, 469-483.

Cadusseau, J., and Roger, M. (1985). Afferent projections to the superior colliculus in the rat, with special attention to the deep layers. J. Hirnforsch. 26, 667-681.

Canteras, N. S., and Goto, M. (1999). Connections of the precommissural nucleus. J. Comp. Neurol. 408, 23-45.

Canteras, N. S., Simerly, R. B., and Swanson, L. W. (1994). Organization of projections from the ventromedial nucleus of the hypothalamus: a Phaseolus vulgaris-leucoagglutinin study in the rat. J. Comp. Neurol. 348, 41-79.

Canteras, N. S., and Swanson, L. W. (1992). The dorsal premammillary nucleus: an unusual component of the mammillary body. Proc. Natl. Acad. Sci. U.S.A. 89, 10089-10093.

Carlson, J. D., Iacono, R. P., and Maeda, G. (2004). Nociceptive excited and inhibited neurons within the pedunculopontine tegmental nucleus and cuneiform nucleus. Brain Res. 1013, 182-187.

Carvalho-Netto, E. F., Markham, C., Blanchard, D. C., Nunes-de-Souza, R. L., and Blanchard, R. J. (2006). Physical environment modulates the behavioral responses induced by chemical stimulation of dorsal periaqueductal gray in mice. Pharmacol. Biochem. Behav. 85, 140-147.

Chubb, M. C., and Fuchs, A. F. (1982). Contribution of y group of vestibular nuclei and dentate nucleus of cerebellum to generation of vertical smooth eye movements. J. Neurophysiol. 48, 75-99.

Coizet, V., Dommett, E. J., Redgrave, P., and Overton, P. G. (2006). Nociceptive responses of midbrain dopaminergic neurones are modulated by the superior colliculus in the rat. Neuroscience 139, 1479-1493.

Coizet, V., Graham, J. H., Moss, J., Bolam, J. P., Savasta, M., McHaffie, J. G., Redgrave, P., and Overton, P. G. (2007). Short-latency visual input to the subthalamic nucleus is provided by the midbrain superior colliculus. J. Neurosci. 29, 5701-5709.

Comoli, E., Favaro, P. D. N., and Mercez, P. L. C. (2010). "Superior colliculus: an important neural site involved in motivated behaviors," in Proceedings of the 40th Annual Meeting of the Society for Neuroscience, abstr. 813.17, San Diego, CA.

Cornwall, J., Cooper, J. D., and Phillipson, O. T. (1990). Afferent and efferent connections of the laterodorsal tegmental nucleus in the rat. Brain Res. Bull. 25, 271-284.

Corvisier, J., and Hardy, O. (1993). Distribution of synaptic terminals from prepositus neurones on the collicular maps. Neuroreport 4, 511-514.

Dean, P., Redgrave, P., Sahibzada, N., and Tsuji, K. (1986). Head and body movements produced by electrical stimulation of superior colliculus in rats: effects of interruption of crossed tectoreticulospinal pathway. Neuroscience 19, 367-380.

Dean, P., Redgrave, P., and Westby, G. W. M. (1989). Event or emergency? Two response systems in the mammalian superior colliculus. Trends Neurosci. 12, 137-147.

Dillon, L. S. (1962). Comparative notes on the cerebellum of the monotremes. I. Contribution toward a phylogeny of the monotremes. I. Contribution toward a phylogeny of the mammalian brain. J. Comp. Neurol. 118, 343-353.

Druga, R., and Syka, J. (1984). Projections from auditory structures to the superior colliculus in the rat. Neurosci. Lett. 45, 247-252

Favaro, P. D. N., Gouvea, T. S., De Oliveira, S. R., Vautrelle, N., Redgrave, P., and Comoli, E. (2011). The influence of vibrissal somatosensory processing in rat superior colliculus on prey capture. Neuroscience 176 318-327.

Ficalora, A. S., and Mize, R. R. (1989). The neurons of the substantia nigra and zona incerta which project to the superior colliculus are GABA immunoreactive: a double-label study using GABA imunocytochemistry and lectin retrograde transport. Neuroscience 29 567-581.

Furigo, I. C., De Oliveira, W. F., De Oliveira, A. R., Comoli, E., Baldo, M. V., Mota-Ortiz, S. R., and Canteras, N. S. (2010). The role of the superior colliculus in predatory hunting. Neuroscience 165, 1-15.

Gaither, N. S., and Stein, B. E. (1979). Reptiles and mammals use similar sensory organizations in the midbrain. Science 205, 595-597.

Garcia Del Caño, G., Gerrikagoitia, I. and Martínez-Millán, L. (2000). Morphology and topographical organization of the retrospleniocollicular connection: a pathway to relay contextual information from the environment to the superior colliculus. J. Comp. Neurol. 425, 393-408.

Gauriau, C., and Bernard, J. F. (2002). Pain pathway and parabrachial circuits in the rat. Exp. Physiol. 87, 251-258.

Glickstein, M. (2003). Subcortical projections of the parietal lobes. $A d v$. Neurol. 93, 43-55.

Gruart, A., and Delgado-García, J. M. (1994). Signalling properties of identified deep cerebellar nuclear neurons related to eye and head movements in the alert cat. J. Physiol. 478(Pt 1), 37-54.

Harting, J. K., Updyke, B. V., and Van Lieshout, D. P. (1992). Corticotectal projections in the cat: anterograde transport studies of twentyfive cortical areas. J. Comp. Neurol. 324, 379-414.

Harvey, A. R., and Worthington, D. R. (1990). The projection from different visual cortical areas to the rat superior colliculus. J. Comp. Neurol. 298, 281-292.

Henkel, C. K., and Schneiderman, A. (1988). Nucleus sagulum: projections of a lateral tegmental area to the inferior colliculus in the cat. $J$. Comp. Neurol. 271, 577-588.

Hoffer, Z. S., Arantes, H. B., and Roth, R. L. Alloway, K. D. (2005). Functional circuits mediating sensorimotor integration: quantitative comparisons of projections from rodent barrel cortex to primary motor cortex, neostriatum, superior colliculus, and the pons. J. Comp. Neurol. 488 , 82-100.
Huerta, M. F., Frankfurter, A., and Harting, J. K. (1983). Studies of the principal sensory and spinal trigeminal nuclei of the rat: projections to the superior colliculus, inferior olive, and cerebellum. J. Comp. Neurol. 220, 147-167.

Huerta, M. F., and Harting, J. K. (1982). The projection from the nucleus of the posterior commissure to the superior colliculus of the cat: patchlike endings within the intermediate and deep grey layers. Brain Res. 238 , 426-432.

Hurley, K. M., Herbert, H., Moga, M. M., and Saper, C. B. (1991). Efferent projections of the infralimbic cortex of the rat. J. Comp. Neurol. 308, 249-276.

Itoh, K., Konishi, A., Nomura, S., Mizuno, N., Nakamura, Y., and Sugimoto, T. (1979). Application of coupled oxidation reaction to electron microscopic demonstration of horseradish peroxidase: cobaltglucose oxidase method. Brain Res. 175, 341-346.

Kass, J. H. (1995). The evolution of isocortex. Brain Behav. Evol. 46, 187-196.

Kass, J. H. (2004). Evolution of somatosensory and motor cortex in primates. Anat. Rec. A Discov. Mol. Cell. Evol. Biol. 281A, 1148-1156.

Kass, J. H. (2011). Neocortex in early mammals and its subsequent variations. Ann. N. Y. Acad. Sci. 1225, 28-36.

Kawakura, S., Hattori, S., Higo, S., and Matsuyama, T. (1982). The cerebellar projections to the superior colliculus and pretectum in the cat: an autoradiographic and horseradish study. Neuroscience 7, 1675-1689.

Kelly, J. B., Buckthought, A. D., and Kidd, S. A. (1998). Monaural and binaural response properties of single neurons in the rat's dorsal nucleus of the lateral lemniscus. Hear. Res. 122, 25-40.

Kelly, J. B., Van Del, B. A., and Ito, M. (2009). Anatomical projections of the nuclei of the lateral lemniscus in the albino aat (Rattus norvegicus). J. Comp. Neurol. 512, 573-593.

Killackey, H. P., and Erzurumlu, R. S. (1981). Trigeminal projections to the superior colliculus of the rat. $J$. Comp. Neurol. 201, 221-242.

Kimura, A., Donishi, T., Okamoto, K., and Tamai, Y. (2004). Efferent connections of posterodorsal auditory area in the rat cortex: implications for auditory spatial processing. $\mathrm{Neu}$ roscience 128, 399-419.

King, S. M., Shehab, S., Dean, P., and Redgrave, P. (1996). Differential expression of fos-like 
immunoreactivity in the descending projections of superior colliculus after electrical stimulation in the rat. Behav. Brain Res. 78, 131-145.

Klooster, J., Vrensen, G. F. J. M., Miiller, L. J., and van der Want, J. J. L. (1995). Efferent projections of the olivary pretectal nucleus in the albino rat subserving the pupillary light reflex and related reflexes. A light microscopic tracing study. Brain Res. 688 , 34-46.

Klop, E. M., Mouton, L. J., Ehling, T., and Holstege, G. (2005). Two parts of the nucleus hypoglossi project to two different subdivisions of the dorsolateral periaqueductal gray in cat. $J$. Comp. Neurol. 492, 303-322.

Kolmac, C. I., Power, B. D., and Mitrofanis, J. (1998). Patterns of connections between zona incerta and brainstem in rats. J. Comp. Neurol. 396, 544-555.

Krauthamer, G. M., Grunwerg, B. S., and Krein, H. (1995). Putative cholinergic neurons of the pedunculopontine tegmental nucleus projecting to the superior colliculus consist of sensory responsive and unresponsive populations which are functionally distinct from other mesopontine neurons. Neuroscience 69, 507-517.

Lee, T., and Kim, U. (2012). Descending projections from the dysgranular zone of rat primary somatosensory cortex processing deep somatic input. J. Comp. Neurol. 520, 10211046.

Leichnetz, G. R., and Gonzalo-Ruiz, A. (1987). Collateralization of frontal eye field (medial precentral/anterior cingulate) neurons projecting to the paraoculomotor region, superior colliculus, and medial pontine reticular formation in the rat: a fluorescent double-labeling study. Exp. Brain Res. 68, 355-364.

Li, Y. Q., Takada, M., Kaneko, T., and Mizuno, N. (1995). Premotor neurons for trigeminal motor nucleus neurons innervating the jaw-closing and jaw-opening muscles: differential distribution in the lower brainstem of the rat. J. Comp. Neurol. 356, 563-579.

Li, Y. Q., Takada, M., Kaneko, T., and Mizuno, N. (1996). GABAergic and glycinergic neurons projecting to the trigeminal motor nucleus: a double labeling study in the rat. J. Comp. Neurol. 373, 498-510.

Liu, Y. J., Wang, Q., and Li, B. (2011). Neuronal responses to looming objects in the superior colliculus of the cat. Brain Behav. Evol. 77, 193-205.

Lynch, J. C., Graybiel, A. M., and Lobeck, L. J. (1985). The differential projection of two cytoarchitectonic subregions of the inferior parietal lobule of macaque upon the deep layers of the superior colliculus. $J$. Comp. Neurol. 235, 241-254.

Manger, P. R., Restrepo, C. E., and Innocenti, G. M. (2010). The superior colliculus of the ferret: cortical afferents and efferent connections to dorsal thalamus. Brain Res. 1353, 74-85.

May, P. J. (2006). The mammalian superior colliculus: laminar structure and connections. Prog. Brain Res. 151, 321-378.

May, P. J., Sun, W., and Hall, W. C. (1997). Reciprocal connections between the zona incerta and the pretectum and superior colliculus of the cat. Neuroscience 77, 1091-1114.

McIntyre, D. C., Kelly, M. E., and Staines, W. A. (1996). Efferent projections of the anterior perirhinal cortex in the rat. J. Comp. Neurol. $369,302-318$.

Menendez, L., Bester, H., Besson, J. M., and Bernard, J. F. (1996). Parabrachial area: electrophysiological evidence for an involvement in cold nociception. J. Neurophysiol. 75, 2099-2115.

Meredith, M. A., and Clemo, R. H. (1989). Auditory cortical projection from the anterior ectosylvian sulcus (field AES) to the superior colliculus in the cat: an anatomical and electrophysiological study. J. Comp. Neurol. 289, 687-707.

Montagnini, A., and Treves, A. (2003). The evolution of mammalian cortex, from lamination to arealization. Brain Res. Bull. 60, 387-393.

Moore, R. Y., Weis, R., and Moga, M. M. (2000). Efferent projections of the intergeniculate leaflet and the ventral lateral geniculate nucleus in the rat. J. Comp. Neurol. 420, 398-418.

Nagata, T., and Hayashi, Y. (1984). The visual field representation of the rat ventral lateral geniculate nucleus. $J$. Comp. Neurol. 227, 582-588.

Ndiaye, A., Pinganaud, G., BuisseretDelmas, C., Buisseret, P., and Vandewerf, F. (2002). Organization of trigeminocollicular connections and their relations to the sensory innervation of the eyelids in the rat. J. Comp. Neurol. 448, 373-387.

Nicolelis, M. A., Chapin, J. K., and Lin, R. C. (1992). Somatotopic maps within the zona incerta relay parallel GABAergic somatosensory pathways to the neocortex, superior colliculus, and brainstem. Brain Res. 577, 134-141.
Ohtsuki, H., Tokunaga, A., Ono, K. Hasebe, S., and Tadokoro, Y. (1992). Distribution of efferent neurons projecting to the tectum and cerebellum in the rat prepositus hypoglossi nucleus. Invest. Ophthalmol. Vis. Sci. 33, 2567-2574.

Olucha-Bordonau, F. E., Tervel, V., Bracia-González, J., Ruiz-Torner, A., Valverde-Navarro, A. A., and Martínez-Soriano, F. (2003). Cytoarchitecture and efferent projections of the nucleus incertus of the rat. $J$. Comp. Neurol. 464, 62-97.

Páli, J., Baldauf, Z. A., Szentpétery, Z., Szabó, Z., Herczeg, L., and Görcs, T. J. (2002). Chemoanatomical separation of vibrissal trigeminal primary afferents in the rat: a special central representation of supraorbital vibrissae. Somatosens. Mot. Res. 19 245-254.

Paxinos, G., and Watson, C. (2007). The Rat Brain in Steretaxic Coordinates, 6th Edn. San Diego: Elsevier.

Pieribone, V. A., and Aston-Jones, G. (1988). The iontophoretic application of fluoro-gold for the study of afferents to deep brain nuclei. Brain Res. 475, 259-271.

Redgrave, P., Marrow, L., and Dean, P. (1992). Topographical organization of the nigrotectal projection in rat: evidence for segregated channels. Neuroscience 50, 571-595.

Redgrave, P., Prescott, T. J., and Gurney, K. (1999). The basal ganglia: a vertebrate solution to the selection problem? Neuroscience 89 , 1009-1023.

Reep, R. L., Corwin, J. V., Hashimoto, A., and Watson, R. T. (1987). Efferent connections of the rostral portion of medial agranular cortex in rats. Brain. Res. Bull. 19, 203-221.

Rhoades, R. W., Fish, S. E., Chiaia, N. L., Bennett-Clarke, C., and Mooney, R. D. (1989). Organization of the projections from the trigeminal brainstem complex to the superior colliculus in the rat and hamster: anterograde tracing with Phaseolus vulgaris leucoagglutinin and intraaxonal injection. J. Comp. Neurol. 289, 641-656.

Ricardo, J. A. (1981). Efferent connections of the subthalamic region in the rat. II. The zona incerta. Brain Res. 214, 43-60.

Roldán, M., and Reinoso-Suárez, F. (1981). The cerebellar projections to the superior colliculus in the cat. $J$. Neurosci. 8, 827-834.

Room, P., Russchen, F. T., Groemewegen, H. J., and Lohman, A. H. M. (1985). Efferent connections of the prelimbic (area 32) and the infralimbic (area 25) cortices: an anterograde tracing study in the cat. J. Comp. Neurol. 242, 40-55.

Sahibzada, N., Dean, P., and Redgrave, P. (1986). Movements resembling orientation or avoidance elicited by electrical stimulation of the superior colliculus in rats. J. Neurosci. 6 , 723-733.

Saitoh, K., Ménard, A., and Griller, S. (2007). Tectal control of locomotion, steering, and eye movements in lamprey. J. Neurophysiol. 97, 3093-3108.

Satoh, K., and Fibiger, H. C. (1986). Cholinergic neurons of the laterodorsal tegmental nucleus: efferent and afferent connections. J. Comp. Neurol. 253, 277-302.

Scarnati, E., and Florio, T. (1997). The pedunculopontine nucleus and related structures. Functional organization. Adv. Neurol. 74, 97-110.

Schmued, L. C., and Fallon, J. H. (1986). Fluoro-Gold: a new fluorescent retrograde axonal tracer with numerous unique properties. Brain Res. 377, 147-154.

Sefton, A. J., Dreher, B., and Harvey, A. (2004). "Visual system," in The Rat Nervous System, 3rd Edn, ed. G. Paxinos (Amsterdam: Elsevier), 1082-1202.

Sesack, S. R., Deutch, A. Y., Roth R. H., and Bunney, B. S. (1989). Topographical organization of the efferent projections of the medial prefrontal cortex in the rat: an anterograde tract-tracing study with Phaseolus vulgaris leucoagglutinin. J. Comp. Neurol. 290, 213-242.

Shammah-Lagnado, S. J., Costa, M. S., and Ricardo, J. A. (1992). Afferent connections of the parvocellular reticular formation: a horseradish peroxidase study in the rat Neuroscience 50, 403-425.

Shehab, S., Alzigali, L., Madathil, M., and Redgrave, P. (2007). Pharmacological evidence for an anticonvulsant relay in the rat ventromedial medulla. Eur. J. Neurosci. 26, 2585-2594

Simpson, K., Wang, Y., and Lin, R. C. (2008). Patterns of convergence in rat zona incerta from the trigeminal nuclear complex: light and electron microscopic study. J. Comp. Neurol. 507, 1521-1541.

Sokov, A. Y., Lyubashina, O. A., and Panteleev, S. S. (2011). Spinal trigeminal neurons demonstrate an increase in responses to dural electrical stimulation in the orofacial formalin test. J. Headache Pain 13, 75-82.

Sparks, D. L. (1986). Translation of sensory signals into commands for control of saccadic eye movements: role of the primate 
superior colliculus. Physiol. Rev. 66, 118-171.

Stein, B. E. (1981). Organization of the rodent superior colliculus: some comparisons with other mammals. Behav. Brain Res. 3, 175-188.

Stein, B. E. (1984). Development of the superior colliculus. Annu. Rev. Neurosci. 7, 95-125.

Stein, B. E., and Meredith, M. A. (1993). The Merging of the Senses. Cambridge, MA: The MIT Press.

Stephenson-Jones, M., Samuelsson, E., Ericsson, J., Brita, R., and Grillner, S. (2011). Evolutionary conservation of the basal ganglia as a common vertebrate mechanism for action selection. Curr. Biol. 21, 1081-1091.

Swanson, L. W. (2004). Brain Maps III: Structure of the Rat Brain. London: Elsevier.

Swanson, L. W., Cowan, W. M., and Jones, E. G. (1974). An autoradiographic study of the efferent connections of in the ventral lateral geniculate nucleus the albino rat and the cat. J. Comp. Neurol. 156, 143-163.

Takahashi, L. K., Chan, M. M., Mark, L., and Pilar, M. L. (2008). Predator odor fear conditioning: current perspectives and new directions. Neurosci. Biobehav. Rev. 32, 1218-1227.

Tanaka, K., Otani, K., Tokunaga, A., and Sugita, S. (1985). The reciprocal connections of the suprageniculate nucleus and the superior colliculus in the rat. Neurosci. Res. 3 , 79-85.

Telford, S., Wang, S., and Redgrave, P. (1986). Analysis of nociceptive neurones in the rat superior colliculus using $\mathrm{c}$-fos immunohistochemistry. J. Comp. Neurol. 375, 601-617.

Trejo, L. J., and Cicerone, C. M. (1984). Cells in the pretectal olivary nucleus are in the pathway for the direct light reflex of the pupil in the rat. Brain Res. 300, 49-62.

Updyke, B. V. (1977). Topographic organization of the projections from cortical areas 17, 18, and 19 onto the thalamus, pretectum and superior colliculus in the cat. J. Comp. Neurol. $173,81-122$.

Van Groen, T., and Wyss, J. M. (1992). Connections of the retrosplenial dysgranular cortex in the rat. J. Comp. Neurol. 315, 200-216.

Vaudano, E., Legg, C. R., and Glickstein, M. (1991). Afferent and efferent connections of temporal association cortex in the rat: a horseradish peroxidase study. Eur. J. Neurosci. 3, 317-330.

Vertes, R. P., and Martin, G. F. (1988). Autoradiographic analysis of ascending projections from the pontine and mesencephalic reticular formation and the median raphe nucleus in the rat. J. Comp. Neurol. 275, 11-41.

Vertes, R. P., Martin, G. F., and Waltzer, R. (1986). An autoradi- ographic analysis of ascending projections from the medullary reticular formation in the rat. Neuroscience 19, 873-398.

Wang, S., and Redgrave, P. (1997). Microinjections of muscimol into lateral superior colliculus disrupt orienting and oral movements in the formalin model of pain. Neuroscience 81, 967-988.

Waterhouse, B. D., Border, B., Wahl, L., and Mihailoff, G. A. (1993). Topographic organization of rat locus coeruleus and dorsal raphe nuclei: distribution of cells projecting to visual system structures. J. Comp. Neurol. 336, 345-361.

Westby, G. W., Keay, K. A., Redgrave, P., Dean, P., and Bannister, M. (1990). Output pathways from the rat superior colliculus mediating approach and avoidance have different sensory properties. Exp. Brain Res. 81, 626-638.

Wiberg, M. (1992). Reciprocal connections between the periaqueductal gray matter and other somatosensory regions of the cat midbrain: a possible mechanism of pain inhibition. Ups. J. Med. Sci. 97, 37-47.

Wise, S. P., and Jones, E. G. (1977) Somatotopic and columnar organization in the corticotectal projection of the rat somatic sensory cortex. Brain Res. 133, 223-235.
Wurtz, R. H., and Albano, J. E. (1980). Visual-motor function of the primate superior colliculus. Annu. Rev. Neurosci. 3, 189-226.

Wyss, J. M., and Sripanidkulchai, K. (2003). The topography of the mesencephalic and pontine projections from the cingulate cortex of the rat. Brain Res. 293, 1-15.

Conflict of Interest Statement: The authors declare that the research was conducted in the absence of any commercial or financial relationships that could be construed as a potential conflict of interest.

Received: 24 January 2012; accepted: 12 March 2012; published online: 03 April 2012.

Citation: Comoli E, Das Neves Favaro $P$, Vautrelle $N$, Leriche $M$, Overton PG and Redgrave P (2012) Segregated anatomical input to sub-regions of the rodent superior colliculus associated with approach and defense. Front. Neuroanat. 6:9. doi: 10.3389/fnana.2012.00009 Copyright (c) 2012 Comoli, Das Neves Favaro, Vautrelle, Leriche, Overton and Redgrave. This is an open-access article distributed under the terms of the Creative Commons Attribution Non Commercial License, which permits noncommercial use, distribution, and reproduction in other forums, provided the original authors and source are credited. 